\title{
CHAPTER 16 \\ THE USE OF THE STOKES-STRUIK APPROXIMATION FOR WAVES OF FINITE HEIGHT
}

\author{
L. E. Borgman \\ Shell Oll Company \\ Technical Services Division \\ Houston, Texas \\ and \\ J. E. Chappelear \\ Shell Development Company \\ Exploration and Production Research Division \\ Houston, Texas
}

\section{ABSTRACT}

A formal approximate solution is derived for the profile and velocity components of a wave with permanent form of finite helght in moderate water depths. The approximation is carried to the third order, sufficlently far to represent all except the very high "design" waves. The relationship of the formulas to others found in the literature is discussed.

The wavelengths and the coefflclents in the third-order series for the wave profile, and the water particle velocities and local accelerations are tabulated for approximately 2000 waves. The depths, heights, and periods for the listed wave conditions vary respectively from 10 to 500 feet, 5 to 40 feet, and 4 to 20 seconds. The range of applicability of the theory is discussed and approximate limits estimated.

As an aid in calculations, tables of the trigonometric and hyperbolıc sines and cosines for integral multiples of the argument are included.

\section{DERIVATION OF FORMULAS}

We wish to construct potential flows satisfying Bernoulli's theorem on the free surface $\eta(x)$ whose shape is one of the unknowns. The problem is one of some difficulty mathematically because of the nonlinear boundary condition. The usual general theorems of existence of solutions for linear problems are not valid and an ad hoc verification of existence of a solution must be made to be sure that the formal solution (Stokes, 1847), which can be rather easily obtained, exists. The existence proof was first carried out by Struik (1926) following the method of Lev1-C1vita (1925) for deep water waves. Struik also obtained formulas for the profile, velocity components, and the necessar: auxiliary functions to relate the parameters in these formulas to the usual physically observed wave characteristics.

Unfortunately all these formulas have algebralc errors, as was first pointed out by Hunt (1953) and then independently by Tanaka (1953), However the results of Hunt and Tanaka do not, at first sight, agree. It seemed advisable to make a new and simpler derivation of these result: 


\section{THE USE OF THE STOKES-STRUIK APPROXIMATION}

\section{FOR WAVES OF FINITE HEIGHT}

in a slightly different way, in order to clear up these discrepancies. A more recent calculation by De (1955) has checked the results of Hunt and extended them to the fifth approximation.

We introduce the device of a moving coordinate system whose velocity, $C$, is the celerity of the waves. In this coordinate system, the motion is steady and two-dimensional. It is then convenient to use complex variables (Lamb, 1932) and a complex potential $w$, whose real and Imaginary parts are the velocity potential $\phi$ and stream function $\psi$,

$$
w(z)=\phi(x, y)+\imath \psi(x, y),
$$

and whose derivative is related to the velocity components $v_{x}$ and $v_{y}$

$$
\frac{d w}{d z}=-v_{x}+\imath v_{y} .
$$

The mathematical problem may be described briefly. We wish to construct a function $w$ of complex variable $z$ which has the properties that $d w / d z$ has a real period $L$,

$$
\frac{d w}{d z}(z)=\frac{d w}{d z}(z+L)
$$

that there is no flow through the bottom,

$$
\operatorname{Im} w=0 \text { on } \operatorname{Im} \boldsymbol{z}=0 \text {, }
$$

and that Bernoulli's equation is satisfied

$$
\frac{1}{2}\left|\frac{d w}{d z}\right|^{2}+g \operatorname{Im} z=\text { Const. }
$$

on the free surface

$$
\operatorname{Im} w=l C \text {. }
$$

We will assume that the solution to the problem has the form

$$
w=C\left\{z+\frac{L}{2 \pi} \sum_{n=1}^{\infty} a^{n} A_{n} \sin n k z\right\},
$$

where $k=2 \pi / L$. We note that equations $(3 a)$ and $(3 b)$ are satisfied if $A_{n}$ are real. The success of this assumption will presently justify the form. We know that Bernoulli's theorem must hold on the line given by putting the imaginary part of $w$ equal to a constant $l C$ in equation (5), whose real and imaginary parts are then parametric equations for the profile. The parameter is $\phi$, the real part of the potential. We see that we will need to invert equation (5) to obtain $z$ as a function of $w$, in order conveniently to satisfy Bernoulli's theorem, equation (4a). It is also necessary to obtain $d w / d z$ as a function of $w$. We will indicate formally how these steps can be carried out, although to justify each step mathematically we would have to investigate the convergence of the assumed solution after we have calculated the values of the coefficients, $A_{n}$. 


\section{COASTAL ENGINEERING}

We differentiate equation (5) wh th respect to $z$ and obtain

$$
\frac{d w}{d z}=C\left[1+\sum_{n=1}^{\infty} a^{n n} n A_{n} \cos n k z\right] .
$$

We assume $z$ as a function of $w$ is given by

$$
C z=w+C \frac{L}{2 \pi} \sum_{n=1}^{\infty} a^{n} B_{n} \sin \frac{n k w}{C},
$$

the justification being that we are able to substitute equation (7) int equation (5) and solve successively for $B_{n}$ as functions of $A_{n}$.

Then we substitute equation (7) in equation (6) and obtain

$$
\frac{d w}{d z}(w)=C\left[1+\sum_{n=0}^{\infty} C_{n} \sin \frac{n k w}{C}\right],
$$

where $C_{n}$ are functions of $a$ and $A_{n}$.

We put $\operatorname{Im} \dot{w}=l C$ in equation (8) and equation (7) and substitute in equation $(4 a)$. We find

$$
\frac{1}{2}\left|1+\sum a^{n} C_{n} \cos \frac{n k}{C}(\phi+\imath l C)\right|^{2}+\frac{g L}{2 \pi C^{2}} \operatorname{Im} z(\phi+\imath l C)=\text { Const. . (s }
$$

We can also put

$$
C^{2}=\sum_{n=0}^{\infty} D_{2 n} a^{2 n} .
$$

since the celerity may be a function of wave helght and depth. Bernoulli's theorem, equation (9), must be valid for all $\phi$ and $a$, and we $r$ put the separate coefficients of $a^{n} \cos m \phi$ equal to zero. When this i: done, the resulting equations may be solved successively to obtain

$$
\begin{aligned}
& A_{1}=1 \\
& A_{2}=-\frac{3}{4(\cosh 2 k l-1)} \\
& A_{3}=-\frac{2(\cosh 2 k l-11)}{16(\cosh 2 k l-1)^{2}} . \\
& D_{0}=\frac{\sinh k l}{\cosh k l} \frac{g L}{2 \pi} \\
& D_{2}=\frac{(2 \cosh 2 k l+2 \cosh 2 k l+5)}{4(\cosh 2 k l-1)} \frac{g L}{2 \pi} \frac{\sinh k l}{\cosh k l} .
\end{aligned}
$$

The profile $\eta(x)$ is found by eliminating $\phi$ from the real and imaginary parts of equation (7), evaluated on $w=\phi+\imath l C$. Then we obtain the $m$ water level $d$ by integration: 


\section{THE USE OF THE STOKES-STRUIK APPROXIMATION}

FOR WAVES OF FINITE HEIGHT

$$
d=\frac{1}{L} \int_{0}^{L} \eta(x) d x=l+\frac{L}{8 \pi} a^{2} \sinh 2 k l,
$$

and the wave height $H$ by some algebra,

$$
H=\eta\left[\frac{L}{2}\right]-\eta(0)
$$

$=\left[2 a \sinh k l+3 a^{3} \frac{4 \cosh ^{3} 2 k l+4 \cosh ^{2} 2 k l+1}{8(\cosh 2 k l-1)^{2}} \sinh k l\right] \frac{L}{2 \pi} \cdot$

Finally, the celerity is given by equation (10),

$$
C^{2}=\frac{\sinh k l}{\cosh k l}\left[1+\frac{2 \cosh ^{2} 2 k l+2 \cosh 2 k l+5}{4(\cosh 2 k l-1)}\right] \frac{g L}{2 \pi},
$$

and the particle velocities from minus the real part and the imaginary part of equation (6),

$$
\begin{aligned}
v_{x}=-\operatorname{Re} \frac{d w}{d z}= & -C\left[1+a \cos k x \cosh k y-\frac{3 \cos 2 k x}{2(\cosh 2 k l-1)} \cosh 2 k y\right. \\
& \left.-\frac{3(2 \cosh 2 k l-1)}{16(\cosh 2 k l-1)^{2}} \cos 3 k x \cosh 3 k y\right],
\end{aligned}
$$

and

$$
\begin{aligned}
v_{y}=\operatorname{Im} \frac{d w}{d z}= & -c\left[a \sin k x \sinh k y-\frac{3 \sin }{2(\cosh 2 k l)} 2 k x \sinh 2 k y\right. \\
& \left.-\frac{3(2 \cosh 2 k l-1)}{16(\cosh 2 k l-1)^{2}} \sin 3 k x \sinh 3 k y\right] .
\end{aligned}
$$

We can transform back into a stationary coordinate system by the substitution

$$
\begin{aligned}
& x=x^{\prime}-c t, \\
& v_{x}=v_{x}^{\prime}-c,
\end{aligned}
$$

and obtain, on dropping the primes,

$$
\begin{aligned}
v_{x} & =C\left[a \cos k(x-c t) \cosh k y-\frac{3 \cos 2 k(x-c t)}{2(\cosh 2 k l-1)} \cosh 2 k y\right. \\
& \left.-\frac{3(2 \cosh 2 k l-1)}{16(\cosh 2 k l-1)^{2}} \cos 3 k(x-c t) \cosh 3 k y\right]
\end{aligned}
$$

and

$$
\begin{aligned}
v_{y}= & -c\left[a \sin k(x-c t) \sinh k y-\frac{3 \sin 2 k(x-c t)}{2(\cosh 2 k l-1)} \sinh 2 k y\right. \\
& \left.-\frac{3(2 \cosh 2 k l-1)}{16(\cosh 2 k l-1)^{2}} \sin 3 k(x-c t) \sinh 3 k y\right] .
\end{aligned}
$$




\section{COASTAL ENGINEERING}

The set of three equations (13), (14), and (15) have as unknowns the three auxiliary parameters $a, k$, and $l$. We see that, given the wave height, the water depth, and the wave period, they may be solved for these auxiliary parameters. The parameter $k$ has a simple interpr tation as seen from these equations since

$$
\frac{2 \pi}{k}=L \text {. }
$$

Also, $l$ and $a$ are related to the depth and helght, respectively.

The equations here given check with those of Hunt and Tanaka. T compare with Hunt and De it is necessary to obtain a as a function of $\mu$, which may be done from the equations for the depth and helght. It is then found that $a$ is an odd function of $\mu$,

$$
a=\sum_{n=0}^{\infty} \mu^{2 n+1} M_{n}(l) \text {. }
$$

To compare with Tanaka, it is only necessary to ldentify his par meter $d$ with our $l$. His statement that his $d$ is the depth is mislead ing, since clearly his $d$ is not the mean water level. Finally, it is relevant to notice that the equations pertaining to the Stokes-Struik theory in the Beach Erosion Board Technical Memoranda 1 and 2 are incorrect, as is pointed out by Hunt.

\section{APPLICATION OF THE THEORY}

After a theory is explicitly stated, normally two steps remain $t$ be completed before the Engineer or Oceanographer can readily apply $t$ theory to an actual problem. First, some procedure must be given to overcome the computational difficulties involved in the use of the theory, and second, the range of applicability must be indicated so that it is possible to determine when the theory should be used.

\section{CONPUTATIONAL FORMULAS}

The Stokes-Struik theory as presented can be put in a somewhat $r$ convenient form for computations as follows. We multiply eq. (13) b: eq. (15) and ignore terms containing powers of a greater than the th Then we divide both sides of the resulting equation by $L^{2} g$ to obtain

$\frac{d}{g T^{2}}=\frac{\tanh k l}{4 \pi^{2}}\left\{k l+\frac{a^{2}}{4}\left[\sinh 2 k l+\frac{k l(\cosh 4 k l+2 \cosh 2 k l+6)}{\cosh 2 k l-1}\right]\right\}$.

Simılarly we multiply eq. (14) by eq. (15) and divıde by $L^{2} g$ ignorın powers of $a$ greater than the third, and obtain 


\section{THE USE OF THE STOKES-STRUIK APPROXIMATION}

\section{FOR WAVES OF FINITE HEIGHT}

$$
\begin{aligned}
\frac{H}{g T^{2}}=\frac{a \tanh k l}{2 \pi^{2}} & \left\{\sinh k l+\frac{a^{2}}{8}\left[\frac{\sinh k l(2 \cosh 4 k l+3 \cosh 2 k l+10)}{\cosh 2 k l-1}\right.\right. \\
& \left.\left.+\frac{\sinh 3 k l}{2} \frac{(3 \cosh 4 k l+4 \cosh 2 k l+2)}{(\cosh 2 k l-1)^{2}}\right]\right\} .
\end{aligned}
$$

Normally at the start of the problem, the depth $d$, wave height $H$, and wave period $T$ are known. The symbols $\pi$ and $g$ are the mathematical constant $3.1415 . .$. and the acceleration due to gravity respectively. Hence $k l$ and $a$ are the only two unknown quantities in equations (23) and (24), and the problem becomes one of solving the two nonlinear equations in two unknowns. While this is difficult by hand, it can be solved easily by iteration on an electronic computer. Once $k l$ and $a$ are known, the other properties of the wave follow immediately. An equation for the wavelength in same general form we have been using is obtained by dividing eq. (15) by $g L$ and remembering that $C=L / T$. Hence

$$
\frac{L}{g T^{2}}=\frac{\tanh k l}{2 \pi}\left[1+a^{2} \frac{(\cosh 4 k l+2 \cosh 2 k l+6)}{4(\cosh 2 k l-1)}\right] \text {. }
$$

The wavelength is thus determined. The wave profile* and the water particle velocities and local accelerations (equations 19 and 20) can be reduced to the convenient form

$$
\eta=d+\eta_{1} \cos \theta+\eta_{2} \cos 2 \theta+\eta_{3} \cos 3 \theta
$$

$v_{x}=v_{1} \cos \theta \cosh k y+v_{2} \cos 2 \theta \cosh 2 k y+v_{3} \cosh 3 \theta \cosh 3 k y$

$v_{y}=v_{1} \sin \theta \sinh k y+v_{2} \sin 2 \theta \sinh 2 k y+v_{3} \sinh 3 \theta \sinh 3 k y$

$a_{x}=\frac{\partial v_{x}}{\partial t}=a_{1} \sin \theta \cosh k y+a_{2} \sin 2 \theta \cosh 2 k y+a_{3} \sin 3 \theta \cosh 3 k y(26)$

$a_{y}=\frac{\partial v y}{\partial t}=-a_{1} \cos \theta \sinh k y-a_{2} \cos 2 \theta \sinh 2 k y-a_{3} \cos 3 \theta \sinh 3 k y$

where $\eta_{1}, \eta_{2}, \eta_{3}, v_{1}, v_{2}, v_{3}, a_{1}, a_{2}$, and $a_{3}$ are functions solely of $L$, $T, k l$ and $a$, and where

$$
\theta=2 \pi\left[\frac{x}{L}-\frac{t}{T}\right], k=\frac{2 \pi}{L}
$$

Explicitly

$$
\begin{aligned}
& \eta_{1}=\frac{L a}{2 \pi}\left[\sinh k l+\frac{a^{2}}{64} \frac{(9 \sinh 5 k l+15 \sinh 3 k l+6 \sinh k l)}{\cosh 2 k l-1}\right. \\
& \eta_{2}=\frac{L a^{2}}{16 \pi} \frac{(\sinh 4 k l+4 \sinh 2 k l)}{(\cosh 2 k l-1)}
\end{aligned}
$$

* Your attention is drawn to the fact that the wave height computed from $H=\eta(0)-\eta(\pi)$ may occasionally be slightly different from the initial wave height chosen at the start of the problem. This discrepancy is due to the approximations made. 


$$
\begin{aligned}
& \eta_{3}=\frac{L a^{3}}{256 \pi} \frac{(3 \sinh 7 k l+15 \sinh 5 k l+27 \sinh 3 k l+39 \sinh k l)}{(\cosh 2 k l-1)^{2}} \\
& v_{1}=\frac{L a}{T} \\
& v_{2}=\frac{3 L a^{2}}{2 T(\cosh 2 k l-1)} \\
& v_{3}=-\frac{3 L a^{3}}{16 T} \frac{(2 \cosh 2 k l-11)}{(\cosh 2 k l-1)^{2}} \\
& a_{1}=\frac{2 \pi v_{1}}{T} \\
& a_{2}=\frac{4 \pi v_{2}}{T} \\
& a_{3}=\frac{6 \pi v_{3}}{T} .
\end{aligned}
$$

As an examination of the equations wlll show, $\eta / L, v_{x} T / L, v_{y} T / L, a_{x} T^{2} / L$ and $a_{y} T^{2} / L$ are all dimensionless and depend only on $k l$ and $a$ or in turr only on $d / g T^{2}$ and $H / g T^{2}$. The same dimensionless form extends to the coefficients.

In all of the preceding formulas, a coordinate system with its origin at the sea floor directly beneath the wave crest when $t=0$ was used. The $x$ axis is horizontal and positive in the direction of wave propagation while the $y$ axis is positive upwards.

When the quantity $d / L$ becomes very large, the hyperbolic functions of $k y$ in the equations become unmanageably large and exceed most tables of hyperbolic functions. In order to avoid these large numbers, a different coordinate system is used whenever $d / T^{2}>2.56$. This is approximately the same as changing the coordinate system whenever $d / L>0.5$. The new coordinate system has its origin at the sea surfact directly below the wave crest when $t=0$, and has its $y$ axis positive downward. The $x$ axis remains the same as before. The equations for the velocities and accelerations assume a slightly different form under this transformation. Let $y^{\prime}$ be the new vertical axis and $y$ be the old one. Then

$$
y=d-y^{\prime}
$$

We substitute this into the previous formulas, dropping the prime, and obtain $v_{x}, v_{y}, a_{x}$, and $a_{y}$ as:

$$
\begin{aligned}
& v_{x}=v_{1} e^{-k y} \cos \theta+v_{2} e^{-2 k y} \cos 2 \theta+v_{3} e^{-3 k y} \cos 3 \theta \\
& v_{y}=v_{1} e^{-k y} \sin \theta+v_{2} e^{-2 k y} \sin 2 \theta+v_{3} e^{-3 k y} \sin 3 \theta
\end{aligned}
$$




\section{THE USE OF THE STOKES-STRUIK APPROXIMATION}

FOR WAVES OF FINITE HEIGHT

$$
\begin{aligned}
& a_{x}=a_{1} e^{-k y} \sin \theta+a_{2} e^{-2 k y} \sin 2 \theta+a_{3} e^{-3 k y} \sin 3 \theta \\
& a_{y}=-a_{1} e^{-k y} \cos \theta-a_{2} e^{-2 k y} \cos 2 \theta-a_{3} e^{-3 k y} \cos 3 \theta
\end{aligned}
$$

\section{TABLES OF COEFFICIENTS}

Although all coefficients in the equations for $\eta, v_{x}, v_{y}, a_{x}$, and $a_{y}$ can be stated in a dimensionless form as functions only of $d / g T^{2}$ and $H \mathrm{gT}^{2}$, a table of the coefficients versus the three variables, wave depth $d$, wave height $H$, and wave perıod $T$, is more convenient for most computations. Accordingly, the coefficients for approximately 2000 different wave conditions are tabulated in Appendix $I$. Water depths from 10 feet to 200 feet are listed in 10-foot intervals, and from 200 feet to 500 feet in 20-foot intervals. Wave heights from 5 to 40 feet in increments of 5 feet, and wave periods from 4 seconds to 20 seconds in increments of 2 seconds are given wherever the Stokes-Struik theory is not demonstrably false. In some cases it was convenient to measure the elevation $y$, from the water surface positive downward instead of from the sea floor positive upward and to use equations (29). The waves for which $y$ should be measured from still water level are indicated in the tables by a minus sign on the wave perlod $(T)$. The negative sign is used here merely as a convention to indicate the transformation of $z$.

A heavy preceding dot has been attached to the wave periods on certain waves.. This dot indicates that we do not actually believe the Stokes-Struik theory is applicable to those particular waves. However, since a frequently used method for computing the velocities and accelerations in waves for which no theory is available consists of interpolation between the several most nearly applicable theories, the coefficients for the wave are included in the table even though the theory does not apply.

The position of the decimal point is indicated at least twice on each page of the table. The decimal point for any other number in the column can be located by comparison.

\section{CIRCULAR AND HYPERBOLIC SINES AND COSINES FOR INTEGRAL MULTIPLES OF THE ARGUMENT}

To facilitate computation of the three-term series, several auxiliary tables were prepared. Table 1 in Appendix II gives $\sin \theta, \sin 2 \theta$, $\sin 3 \theta, \cos \theta, \cos 2 \theta$, and $\cos 3 \theta$ as a function of $\theta$ for each degree of $\theta$ between $0^{\circ}$ and $360^{\circ}$. Table 2 in Appendix II gives sinh $2 \pi y / L$, sinh $4 \pi y / L, \sinh 6 \pi y / L, \cosh 2 \pi y / L, \cosh 4 \pi y / L$, and $\cosh 6 \pi y / L$ as a function of $y / L$ in increments of 0.01 from 0 to 1.0 . These two tables reduce the labor of looking up the functions for a given computation from six entries in a standard table to only two entries. 


\section{COASTAL ENGINEERING}

\section{RANGE OF APPLICABILITY}

Our estimate of the range of applicability of the theory is given Figure 1. For each value of $d / T^{2}$ there is a limiting value of $H / T^{2}$ suc that waves will break before $H / T^{2}$ grows larger. A line connecting thes limiting points is called the breaker index curve. In Figure l, for thi estimation of the breaker index curve, the modified solitary theory was used for $d / T^{2}<0.1$ while the results of an unpublished study made by J. E. Chappelear were used for $d / T^{2}>2.0$. The position of the line in between was estimated and is shown by dashes. This breaker index curve is an obvious upper limit to the use of any wave theory. A somewhat smaller upper boundary can be developed from the wave profile equation. From wave tank studies and from intultion, we are falrly sure that wave have only one maximum per wave cycle, 1,e., the wave crest. Even more stringently, we suspect that the waves do not have any jogs or semisteps in the profile. This is the same as saying that the wave profile should have only one inflection point between the wave crest and trough The boundary line between those waves, as computed by the Stokes-Strulk third approximation, that have three inflection points between their crests and troughs and those that have only one is shown in Figure $I$ as a solid line. Although this criterion strictly is intultive, it seems reasonable to the author. The inflection point boundary and the breake index curve cross at about $d / T^{2}=0.7$. Hence the inflection point criterion is unsuitable for larger $d / T^{2}$ values, and a different criter was developed.

The percent of the wave height above still water level for maximum waves where $d / T^{2}>2.0$ was known by a previous unpublished study. Grap of the percent of wave height above still water level were plotted vers $H / T^{2}$ holding $d / T^{2}$ at a constant value both for the Stokes-Struik third approximation and Chappelear's limiting case. The Stokes-Struik values departed from a smooth curve through the points at about $H / T^{2}=0.45$. The point of departure decreased somewhat with a decrease of $d / T^{2}$. Thi departure line is shown as a dash-dot line in Figure 1, Reid and Bretschneider (1953, p. 12) estimate the second approximation of the Stokes Struik theory to be accurate in deep water for approximately $H / T^{2}<0.3$ Hence the boundary line reaching $H / T^{2}=0.45$ for the third approximatic is reasonably consistent with their estimate.

In the preceding work, the basic formulas were derived by Chappele while the section on the application of the theory together with the various tables were prepared by Borgman. Both authors wish to express thelr appreciation to the Shell Oil Company and the Shell Development Company for permission to publish the paper. 
THE USE OF THE STOKES-STRUIK APPROXIMATION

FOR WAVES OF FINITE HEIGHT

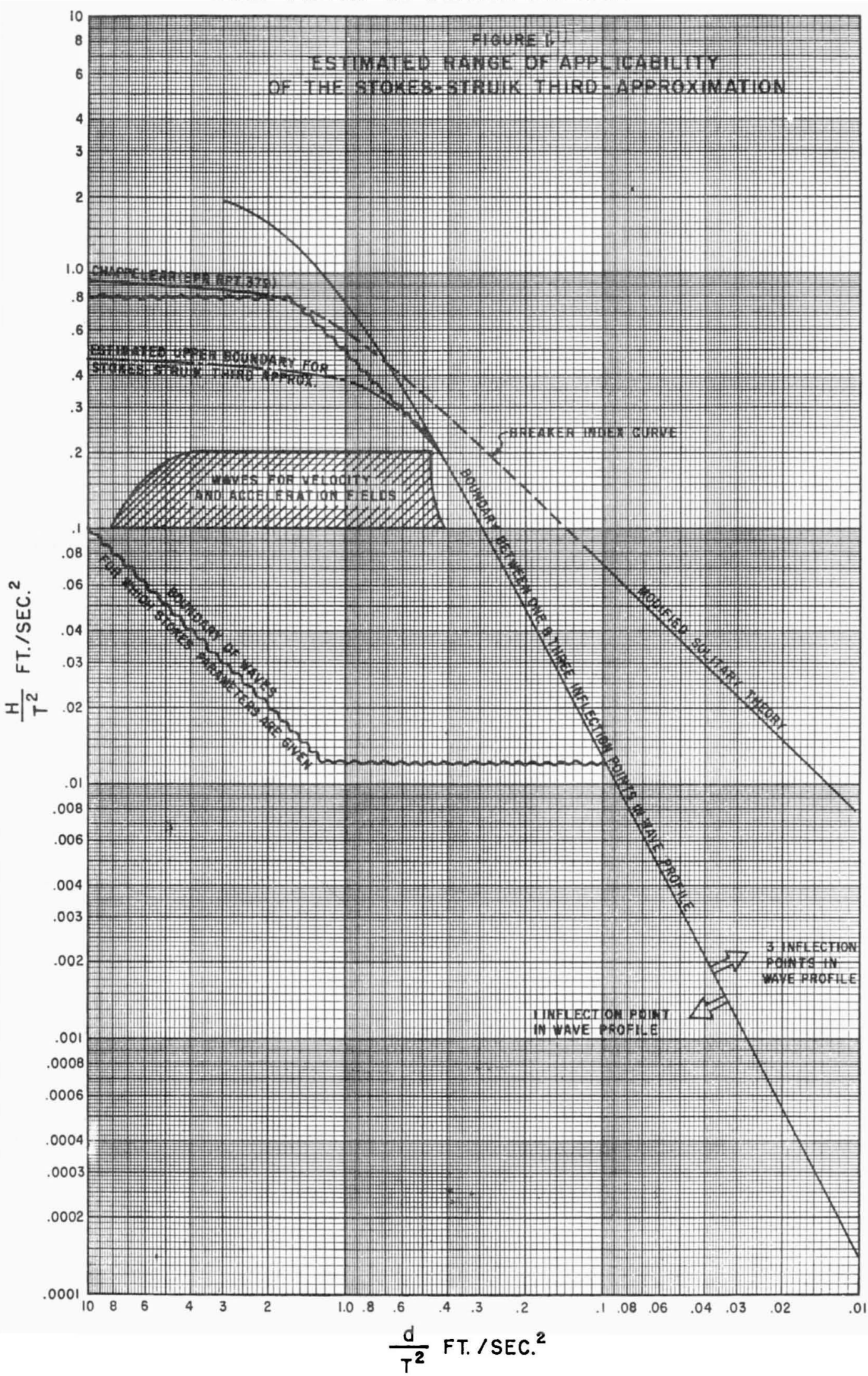




\section{COASTAL ENGINEERING}

\section{REFERENCES}

De, S. C. (1955). Contr, to the theory of Stokes' waves: Proc. Camb. Phil. Soc., vol. 51, pp. 713-736.

Hunt, J. N. (1953). A note on gravity waves of finite amplitude: Quart. Journ. Mech. and Applied Math., vol. VI, Pt. 3, pp. 336-343.

Lamb, Sir Horace (1932). Hydrodynamics, Dover (VI Edıtıon), pp. 66 ff. and $375 \mathrm{ff}$.

Lev1-Civita, Tullio (1925). Determinatıon rigoureuse des ondes permanentes d'ampleur finie; Math. Ann., vol. 43, pp. 264-314.

Reid, R. 0., and Bretschnelder, C. I. (1953). Surface waves and offshore structures: Texas A, and M. Research Foundation, College Station, October 1953.

Stokes, Sir George (1847). On the theory of oscillatory waves: Trans. Camb. Soc., vol. VIII, p. 441.

Struık, D. J. (1926). Determinatıon rigoureuse des ondes irrotationelle periodiques dans un canal a profondeur finle: Math. Ann., vol. XCV, pp. 595-634.

Tanaka, Kiyosh1 (1953). On sea waves: Tech, Rep. of Osaka Univ., \#65, March 1953.

\section{IIST OF SYMBOLS}

$a$

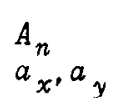

$a_{1}, a_{2}, a_{3}=$

$\mathrm{B}^{n}$

$C_{n}$

$D_{2 n}$

$g$

$H$

$k$

$l=$

$L$

= a mathematical parameter in the Stokes-Struık third approximation. The physical meaning is given by the formulae.

= expansion coefficients to be calculated.

- horizontal and vertical components of the local accelerations of water particles, i.e., $a_{x}=\partial v_{x} / \partial t$, $a_{y}=\partial v_{y} / \partial t ;\left(\mathrm{ft} / \mathrm{sec}^{2}\right)$.

Stokes-Struik third approximation coefficıents for the local accelerations.

= expansion coefficients to be calculated.

$=$ wave celerity, or speed of advance of the waveform (ft/sec).

= expansion coefficients to be calculated.

= still water depth, or depth the water would assume if th waves were calmed down and the water was still (ft).

- expansion coefficients to be calculated.

- acceleration due to gravity (nominally taken as $\left.32.16 \mathrm{ft} / \mathrm{sec}^{2}\right)$.

$=$ wave helght, or vertıcal distance between a crest and th preceding trough (ft).

$=2 \pi / L\left(\mathrm{ft}^{-1}\right)$.

= a mathematical parameter in the Stokes-Struik third approximation. The physical meaning is given by the formulae.

= wavelength, or horizontal distance between two succeeding troughs or crests in the direction of wave propagation (ft). 


\section{THE USE OF THE STOKES-STRUIK APPROXIMATION FOR WAVES OF FINITE HEIGHT}

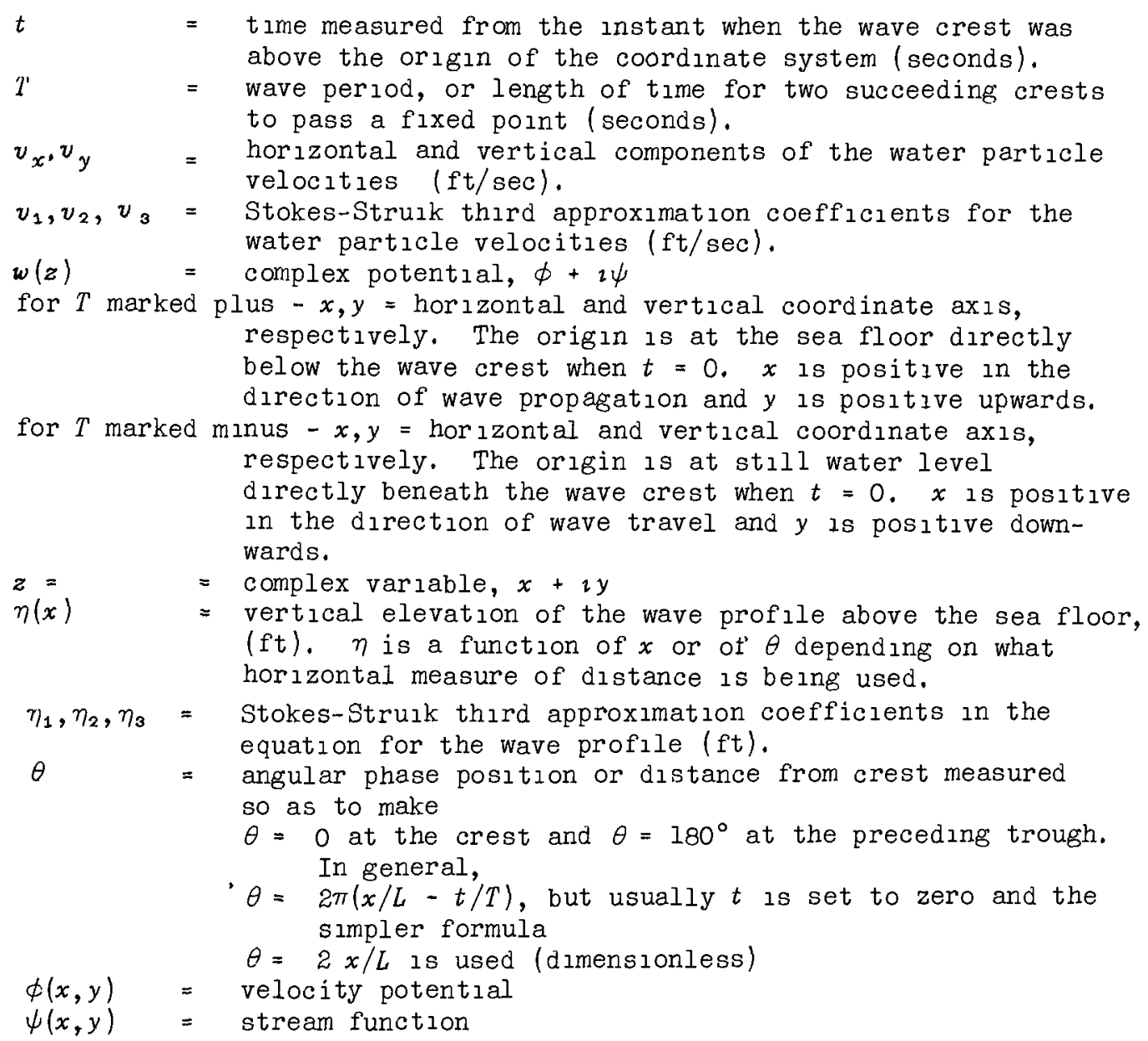

\section{APPENDIX I}

\section{STOKES-STRUIK THIRD-APPROXIMATION COEFFICIENTS FOR AN ASSEMBLAGE OF WAVE CONDITIONS}

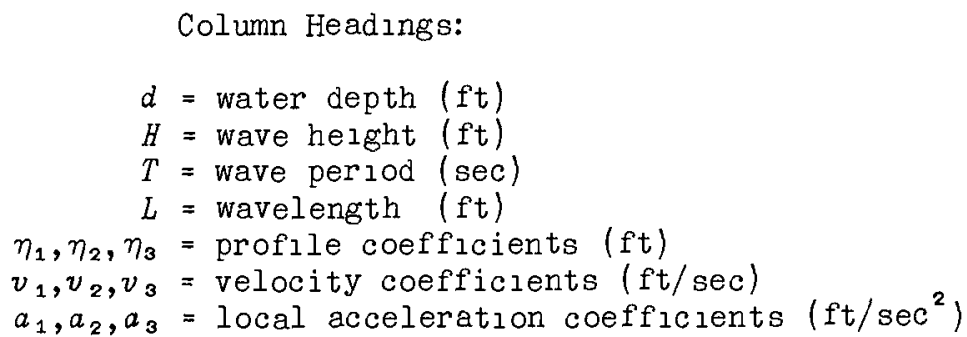

(The reader is referred to the list of symbols for more detalled definitions, and to the text for the mathematical series in which the coefficients are to be used.)

The decimal point position is indlcated in the first line of each depth group and on the first line of each page. The decimal positions of the other numbers in a given column are the same as those where the position is indicated. 


\section{COASTAL ENGINEERING}

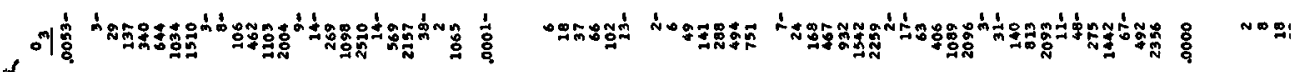

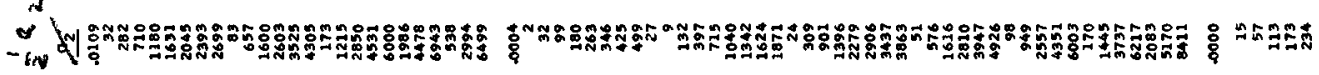

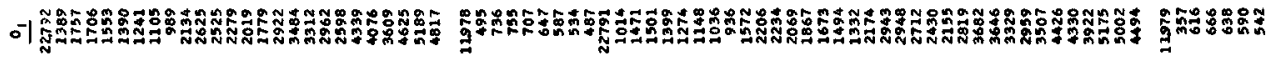

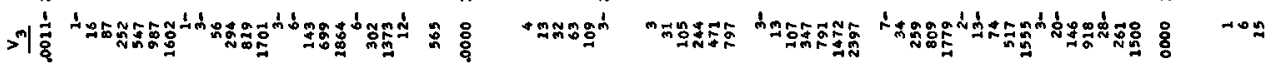

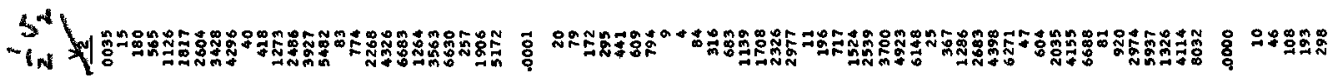

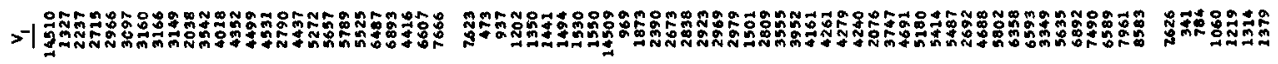

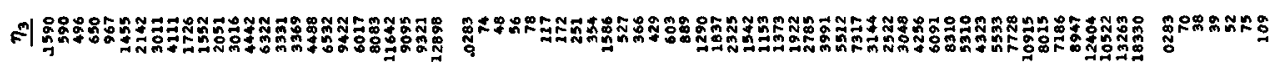

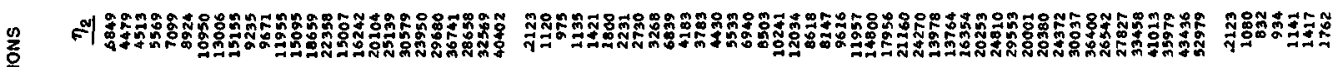

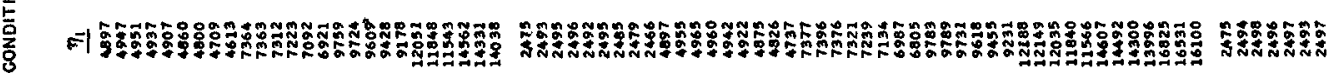

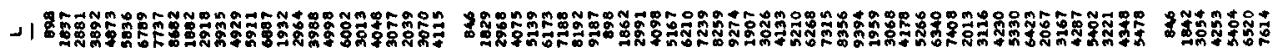

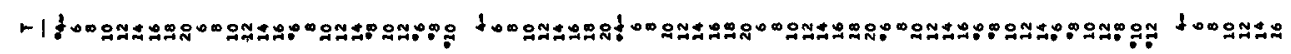

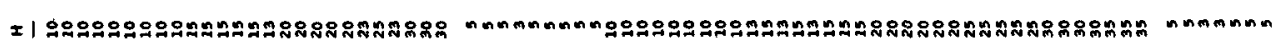

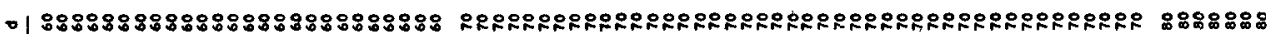

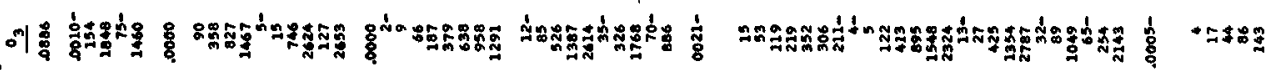

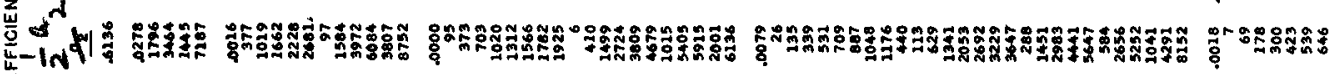
岩

-1 ร

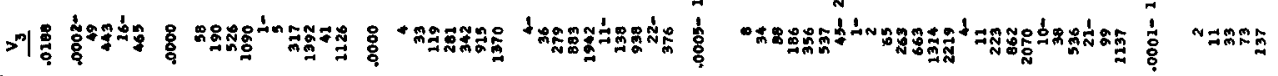
-

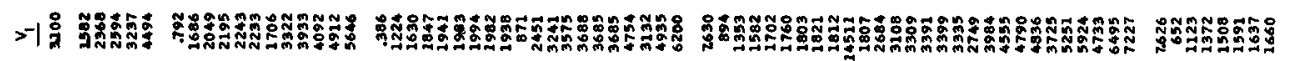

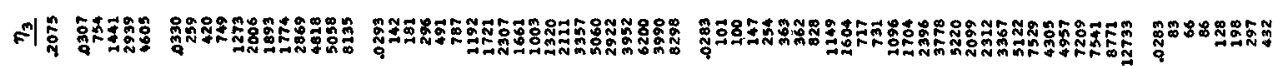

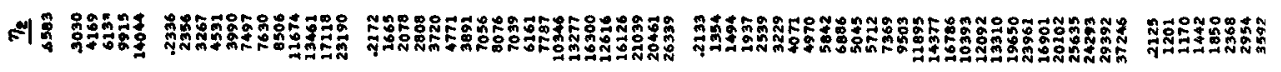

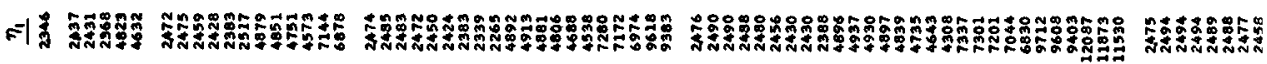

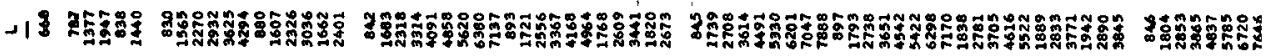

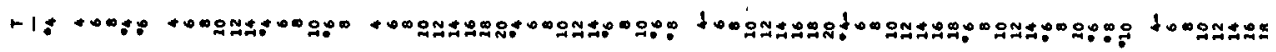

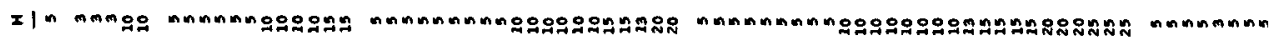

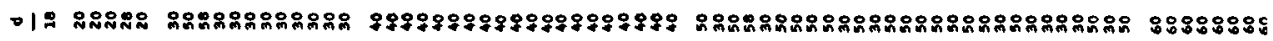


$\rightarrow$ T THE USE OF THE STOKES-STRUIK APPROXIMATION

FOR WAVES OF FINITE HEIGHT

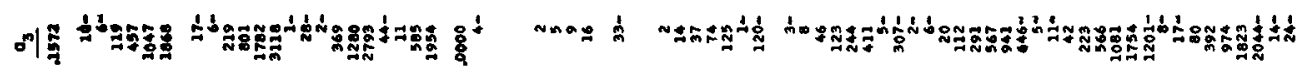
d|ำ -

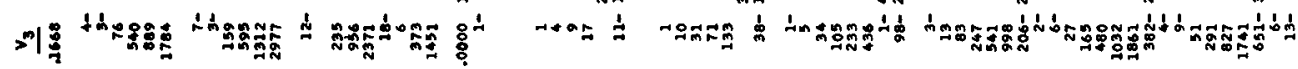

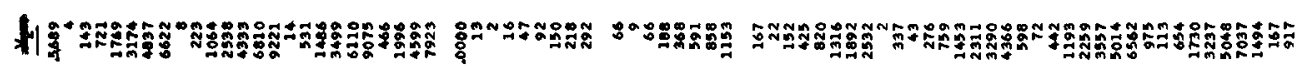

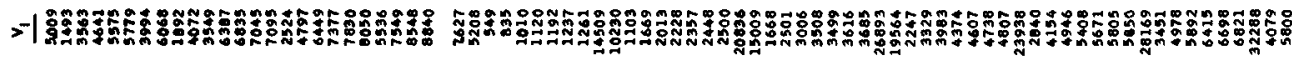

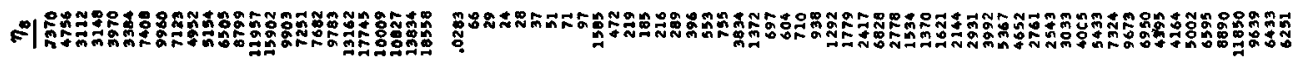

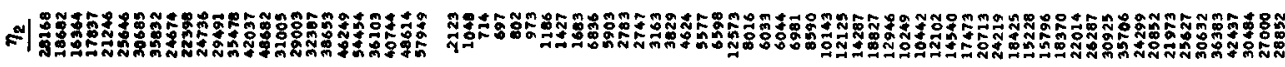

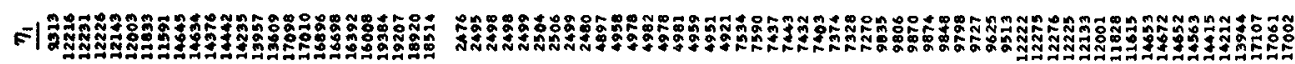

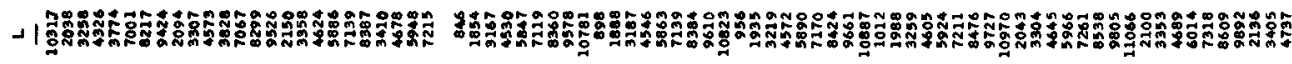

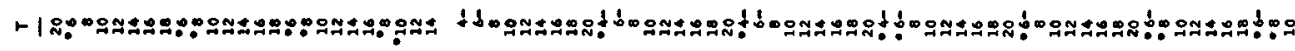

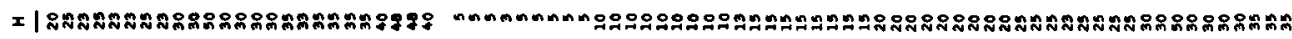

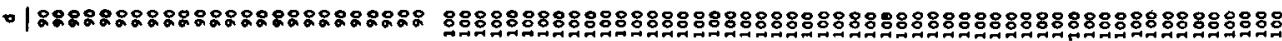

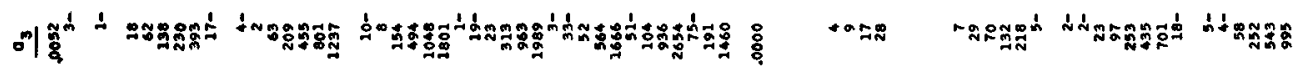

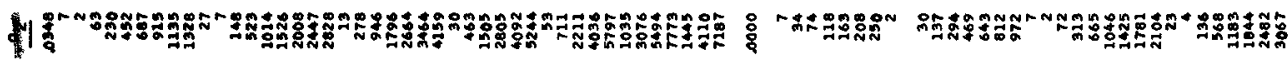

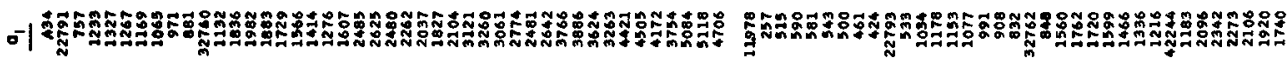

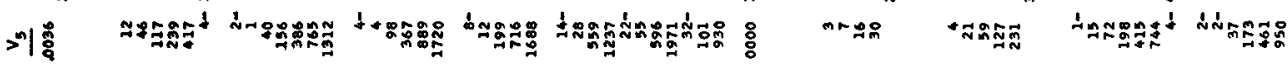

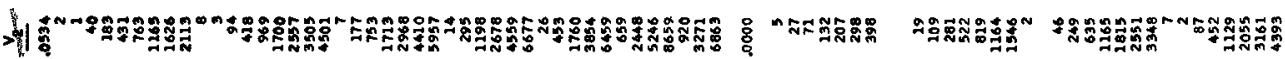

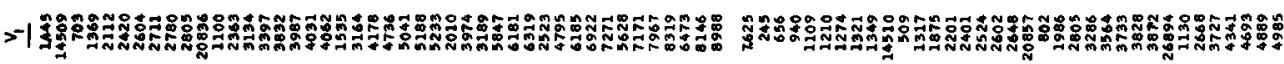

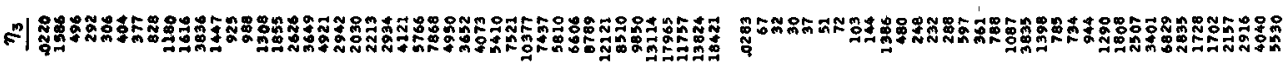

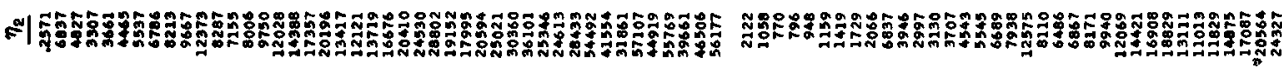

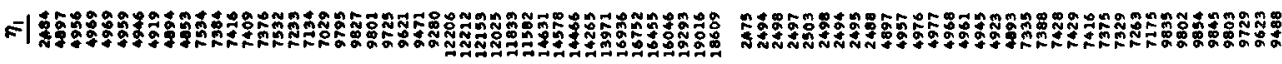

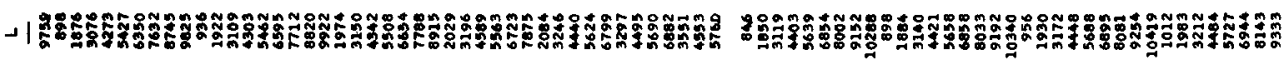
ค| I| || 


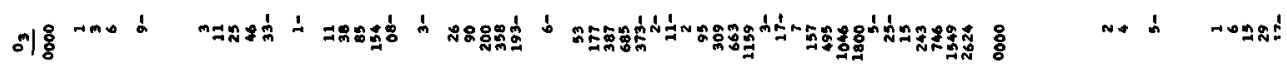

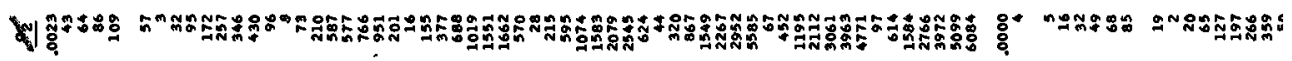

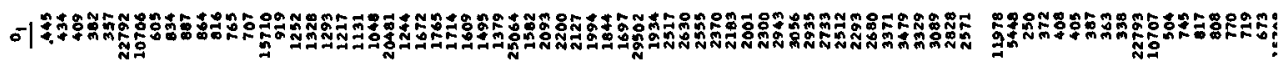

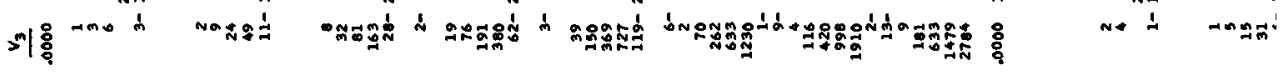

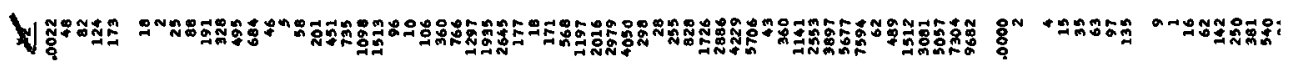

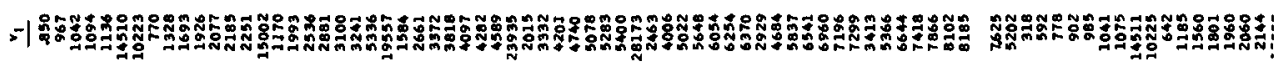
:

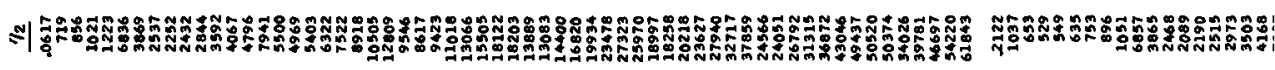

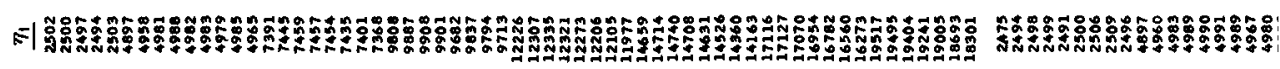

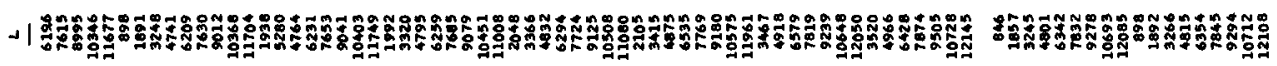
- |

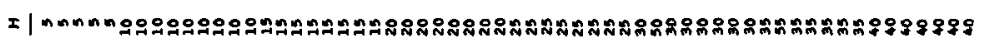

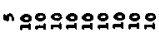

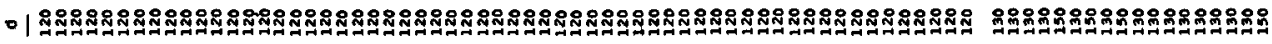

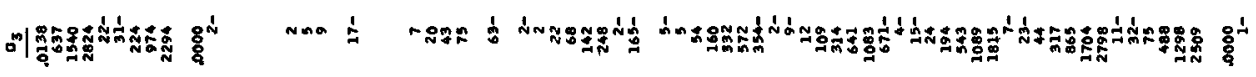

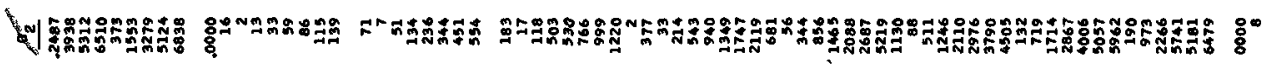

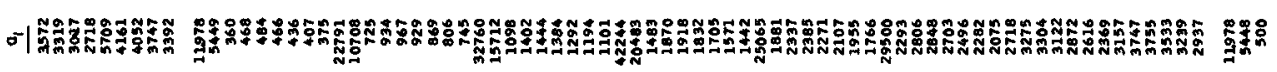

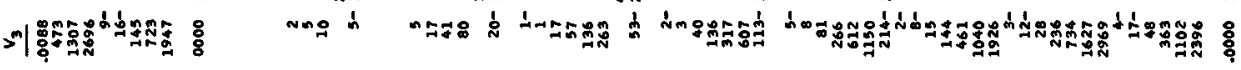

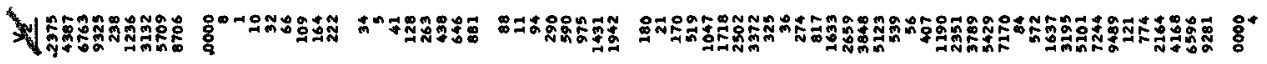

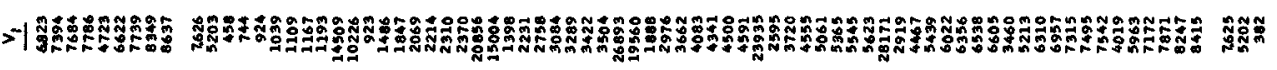

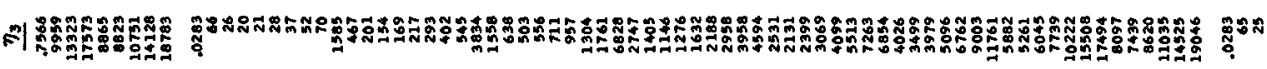

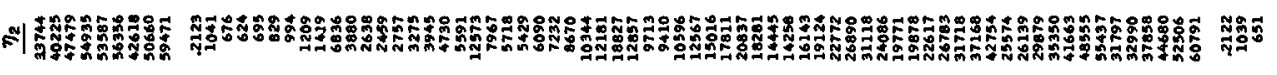

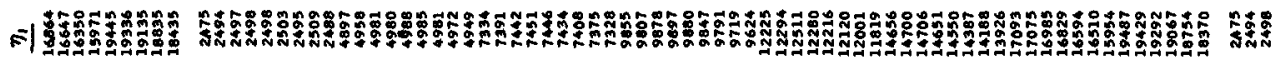

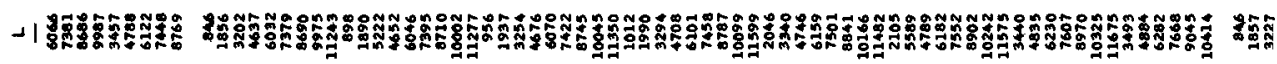
- | 工|

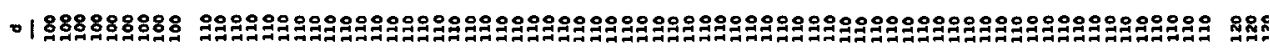


THE USE OF THE STOKES-STRUIK APPROXIMATION FOR WAVES OF FINITE HEIGHT

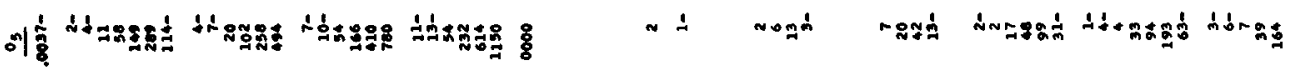

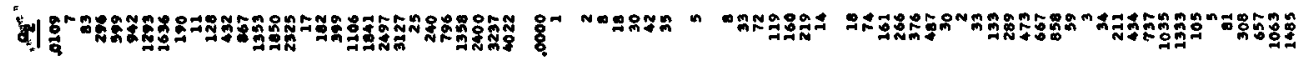

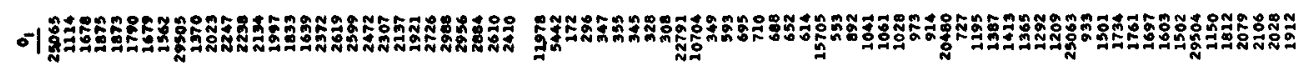

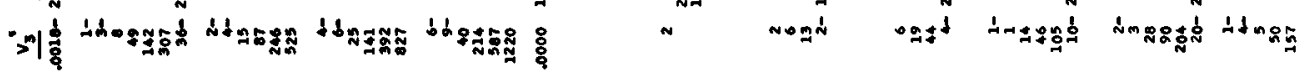

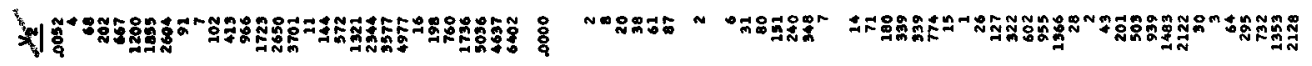

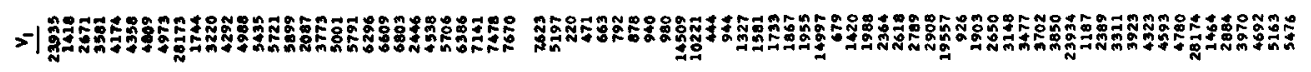

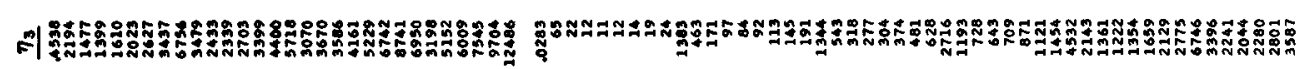

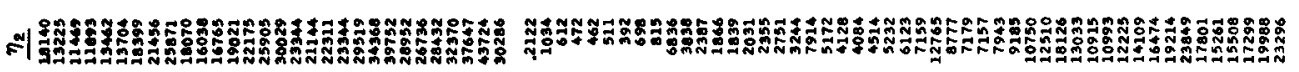

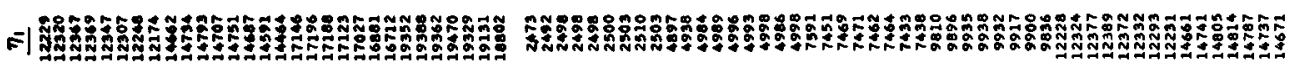

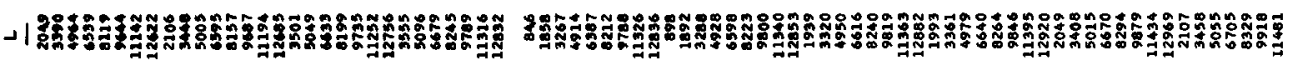
-1 |

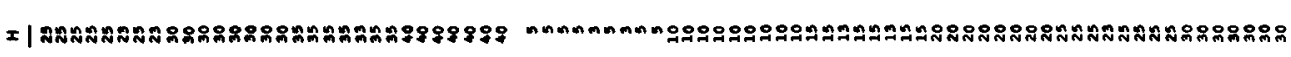

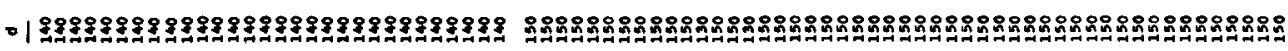

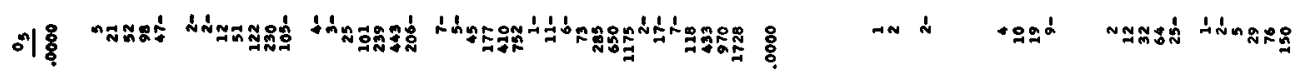

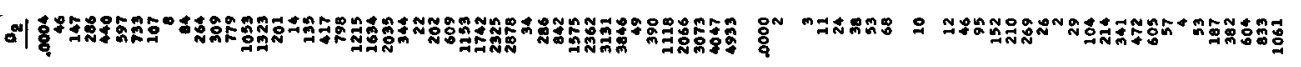

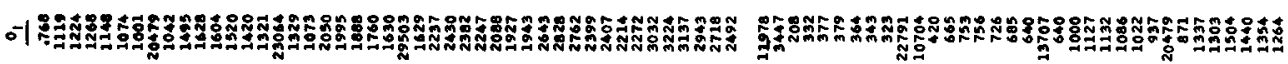

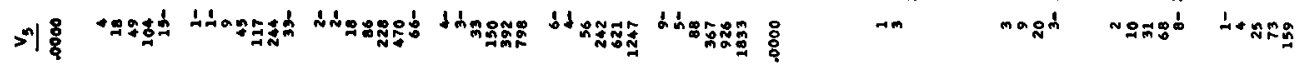

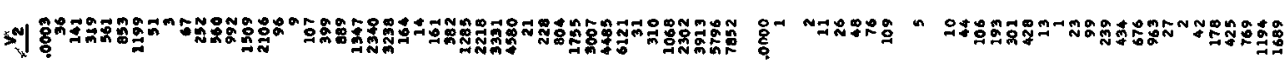
>1:

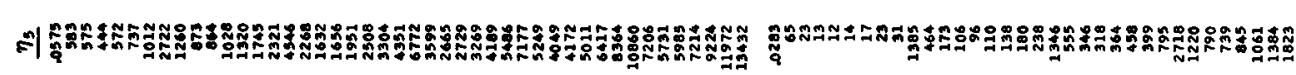

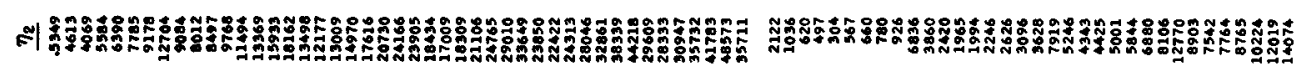
-1 -1

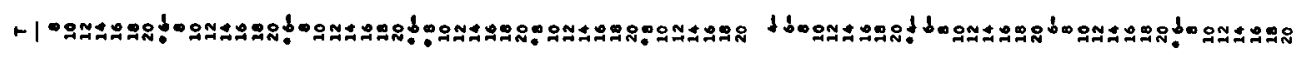

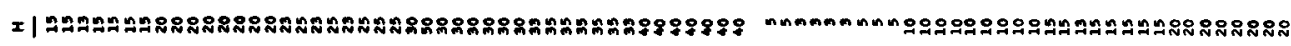
- | 
$-4$

COASTAL ENGINEERING

$-1 n$

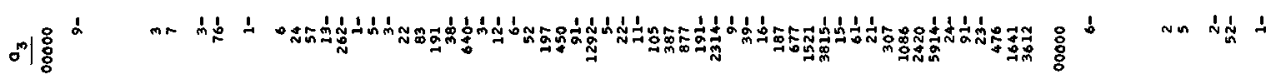

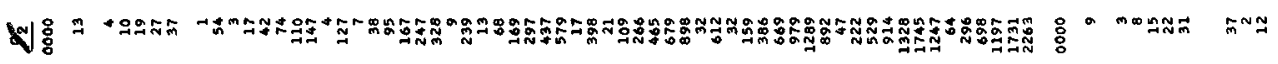

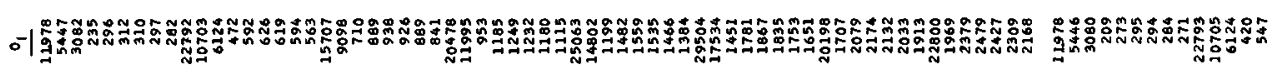

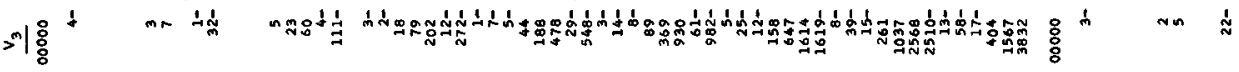

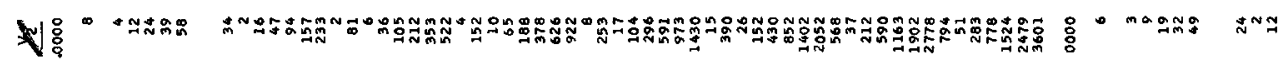

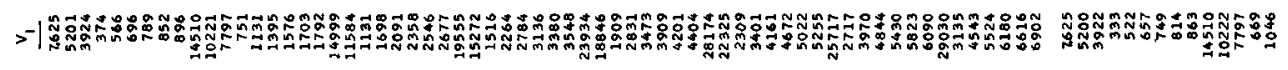

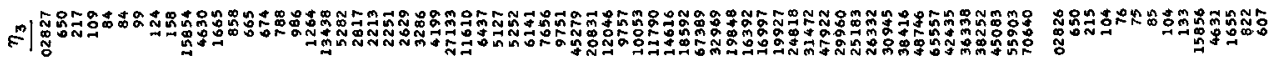

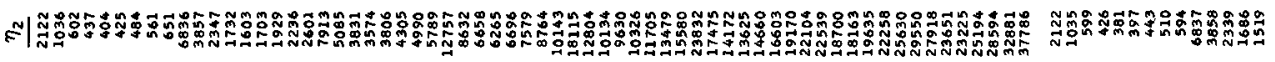

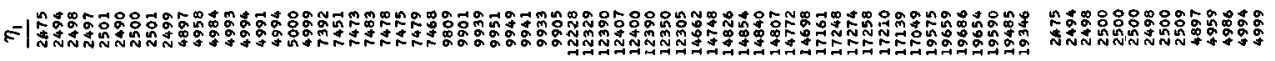

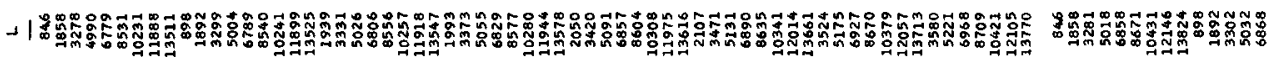
-1|S1

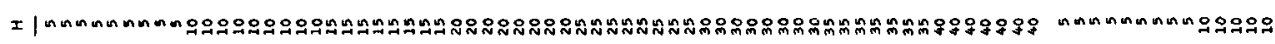

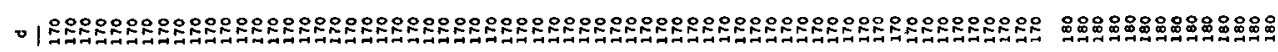

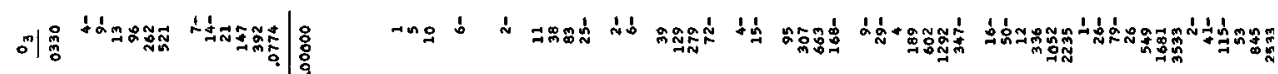

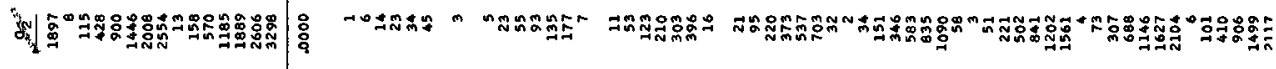

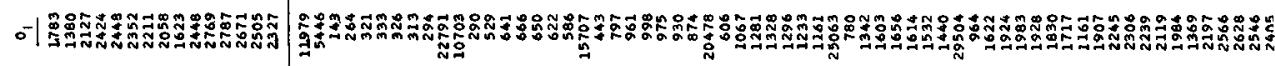

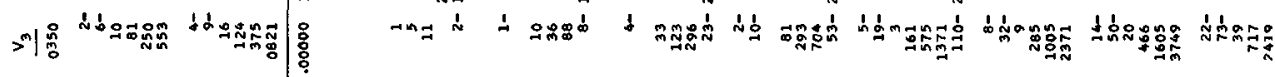

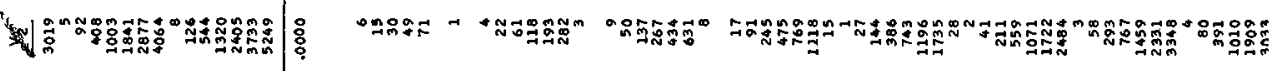

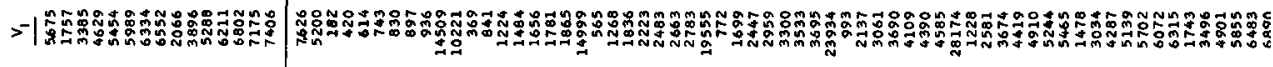

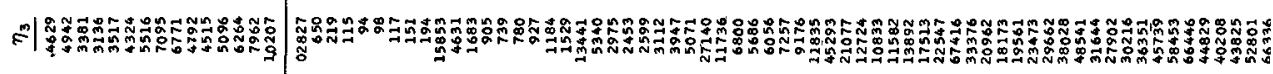

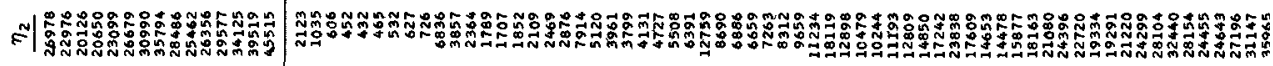

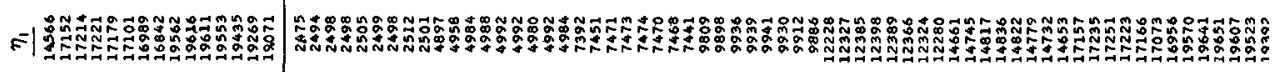

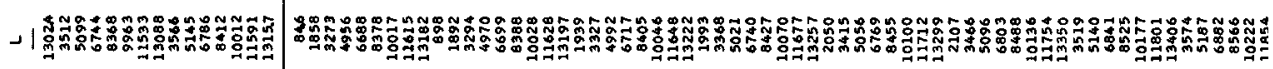
十| |

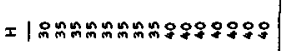
- | 
THE USE OF THE STOKES-STRUIK APPROXIMATION FOR WAVES OF FINITE HEIGHT

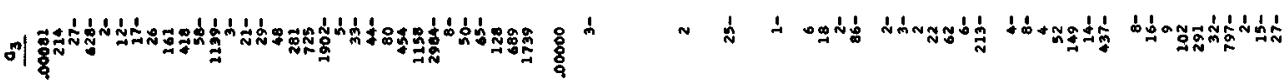

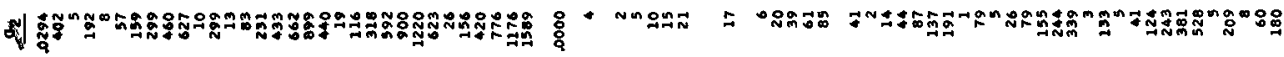

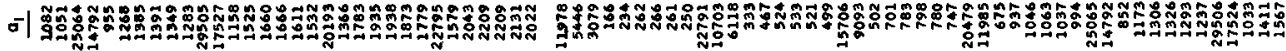

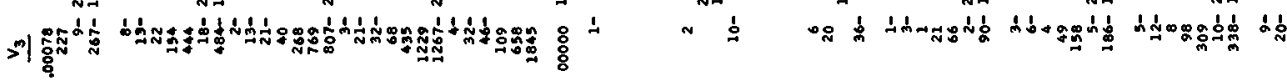

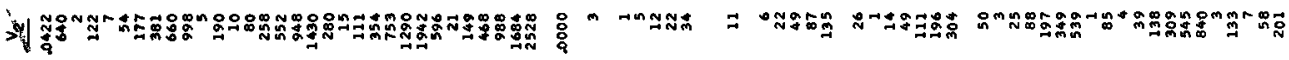

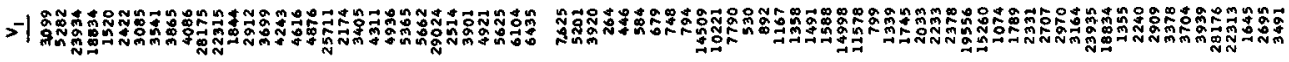

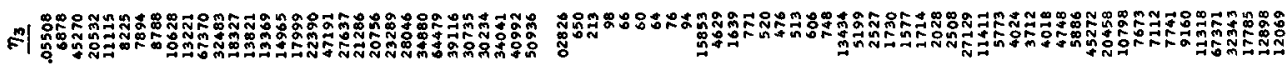

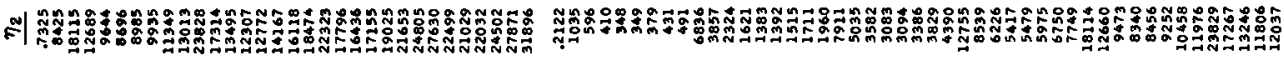

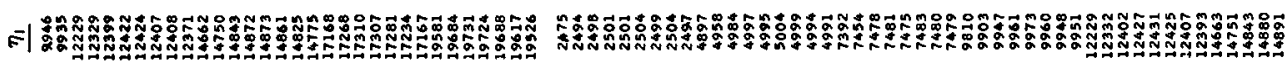

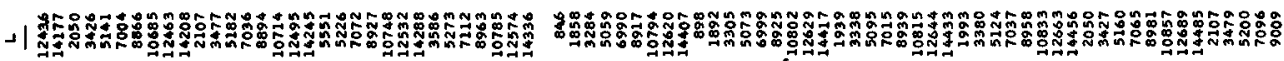

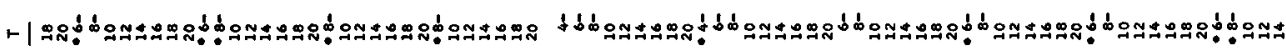
둥ำ

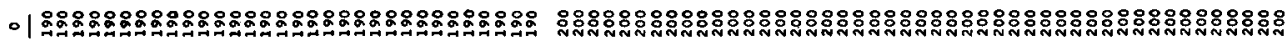

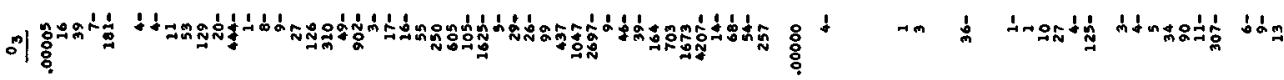

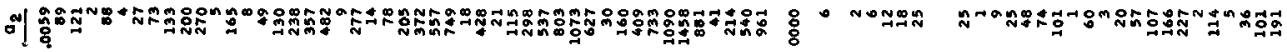

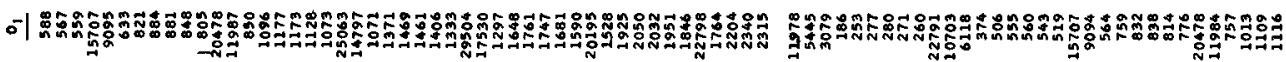

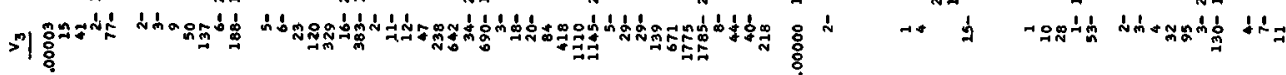

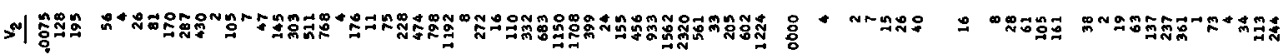
-1

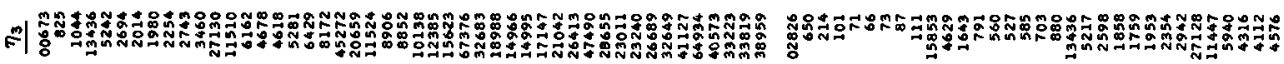

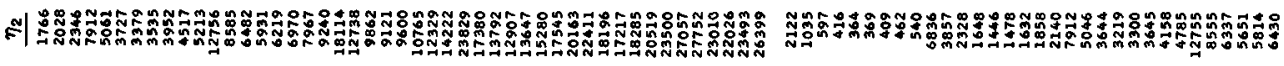

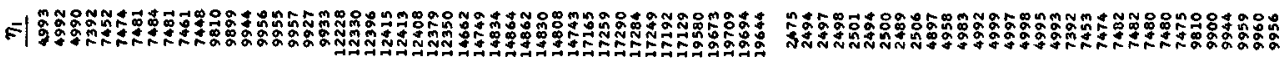

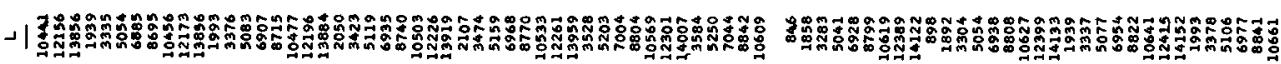
-1

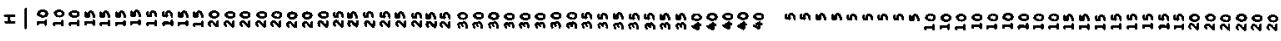
- | 


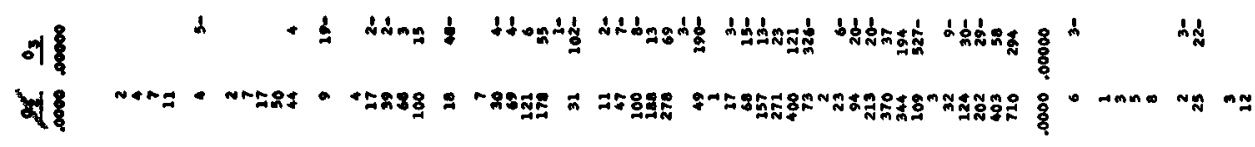

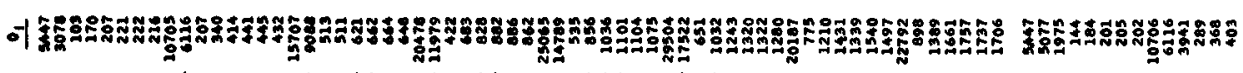

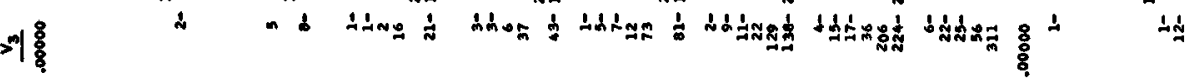
才条 NM

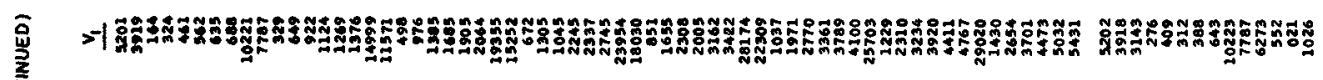

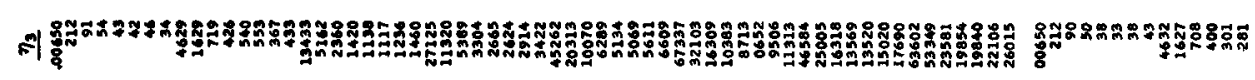

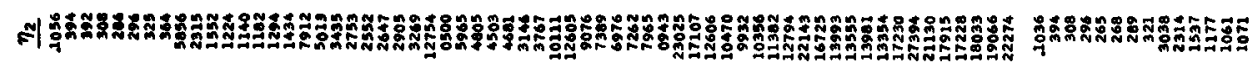

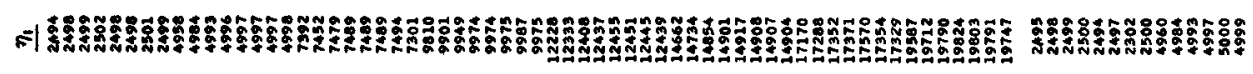

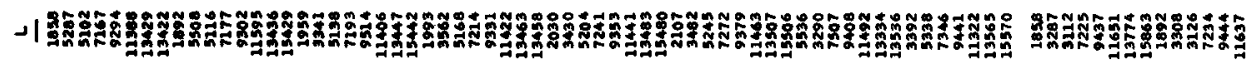

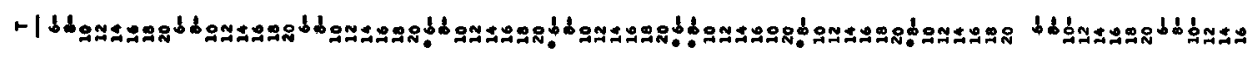

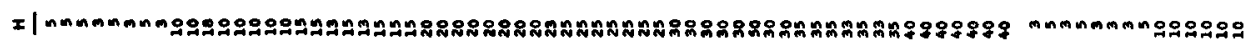

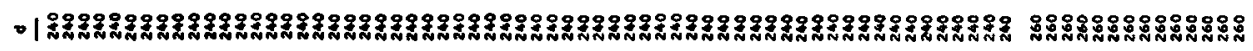

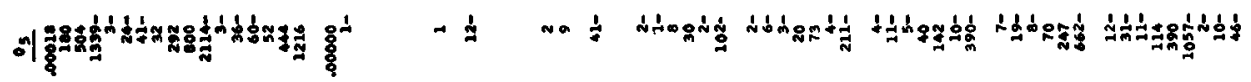

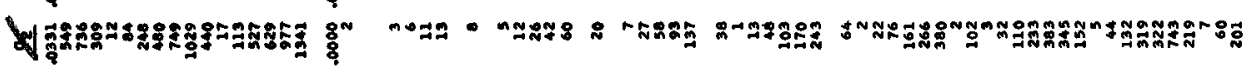

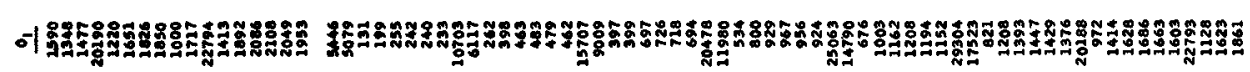

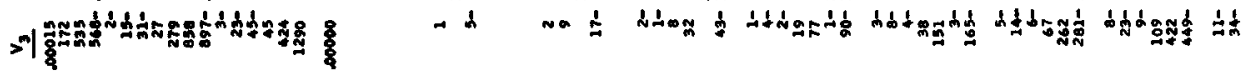
W

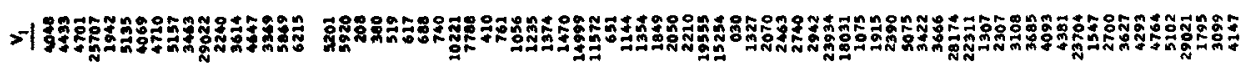

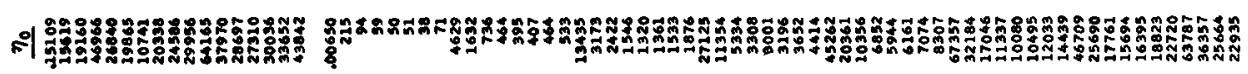

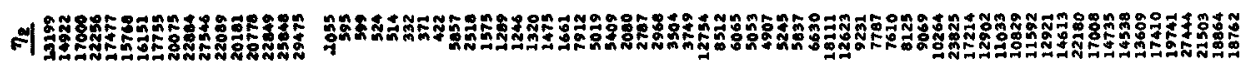

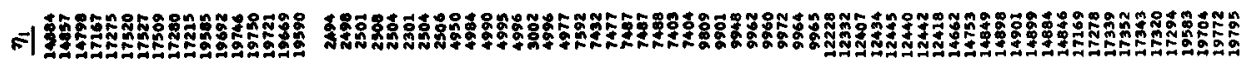

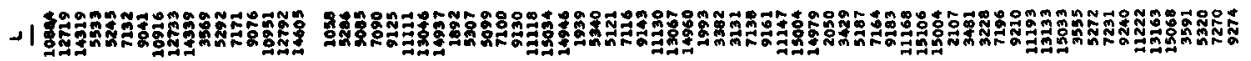

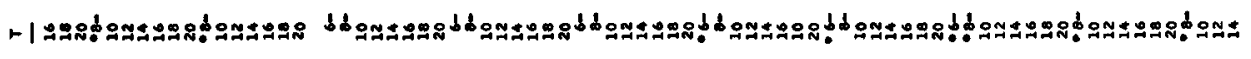
ㄷำ

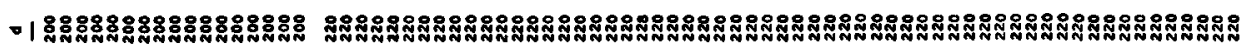


$\therefore$ THE USE OF THE STOKES-STRUIK APPROXIMATION FOR WAVES OF FINITE HEIGHT

品行

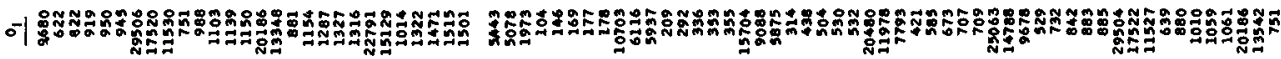

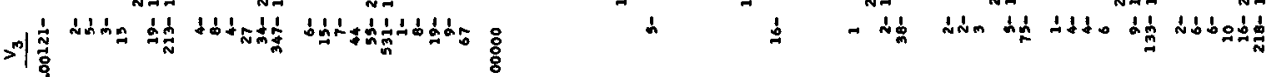

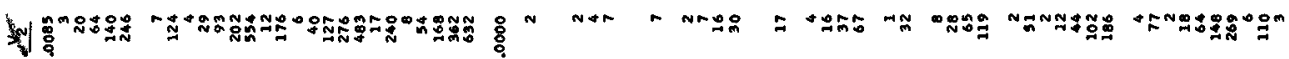

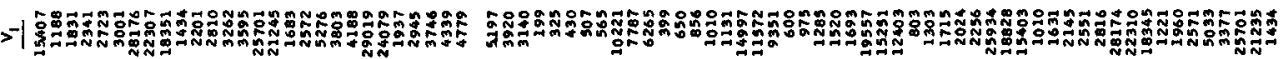

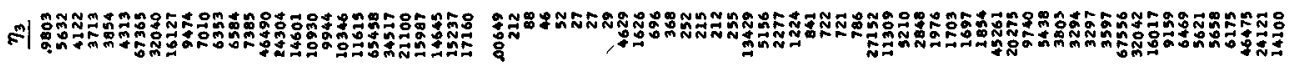

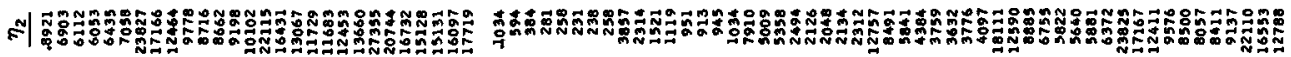

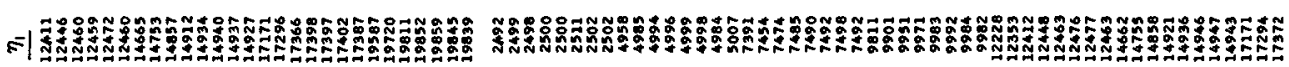

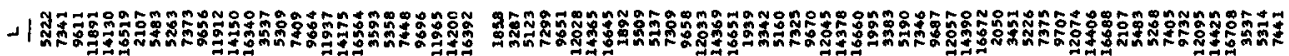
-1

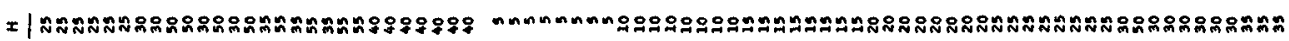
- |

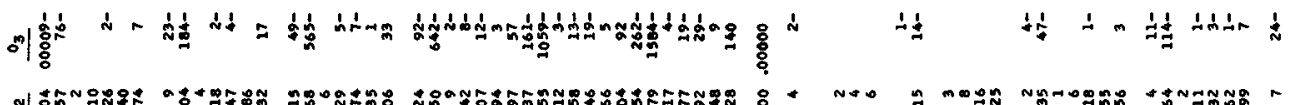

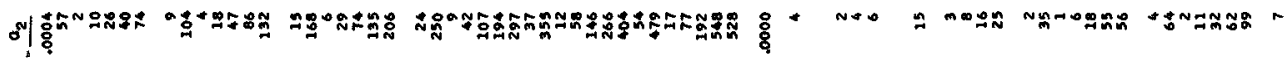

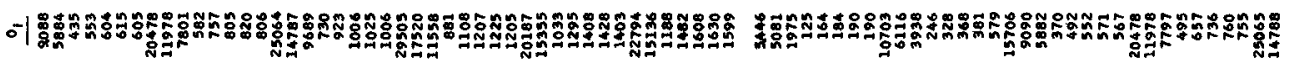

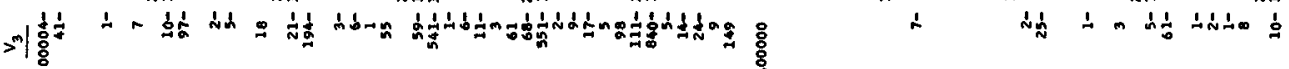
겐

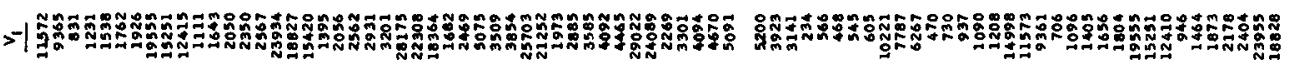

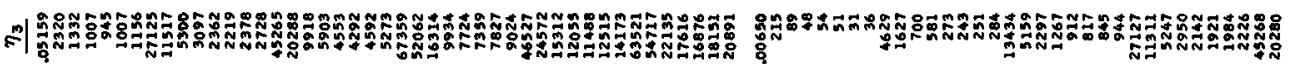

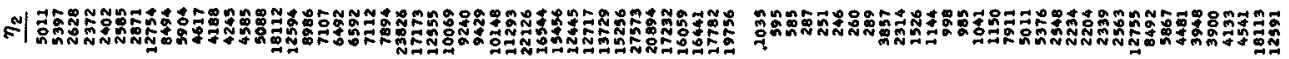

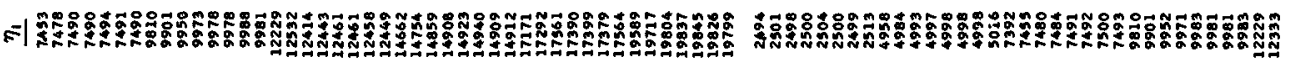

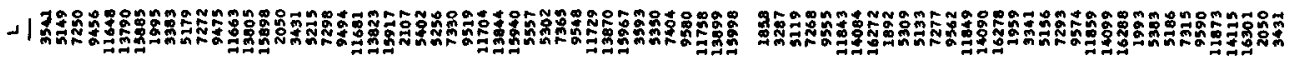

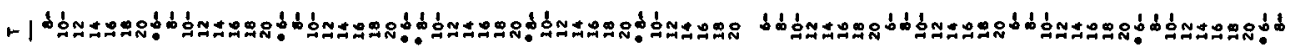

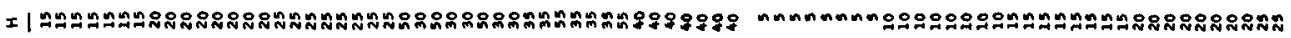

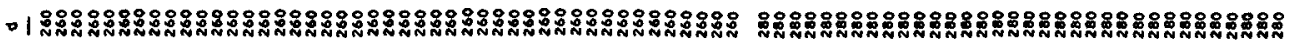




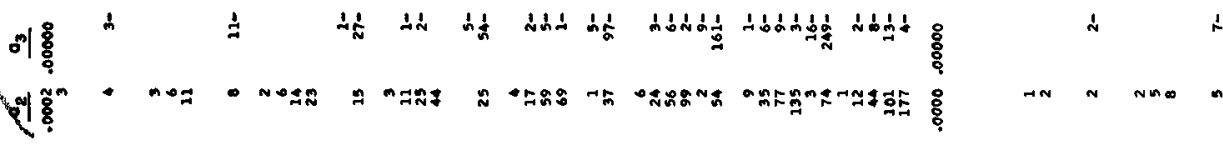

-1 $>1$

ได้

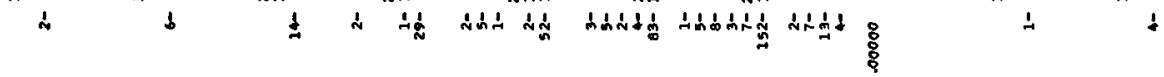

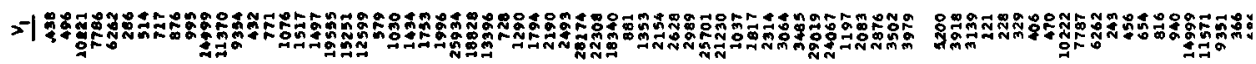

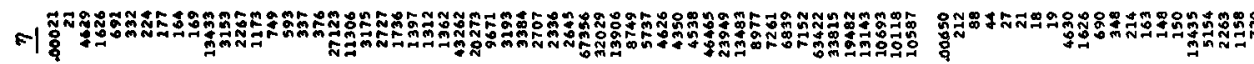

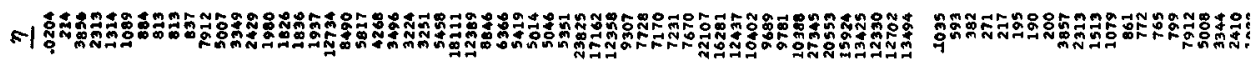

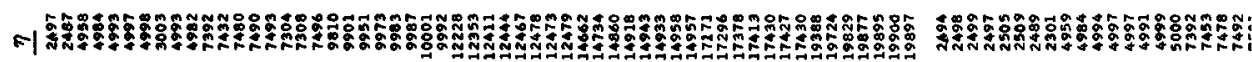

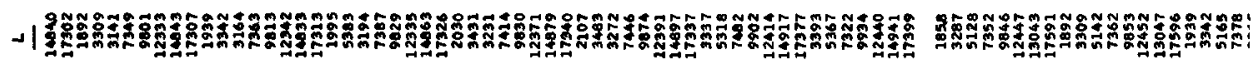
H | x| -

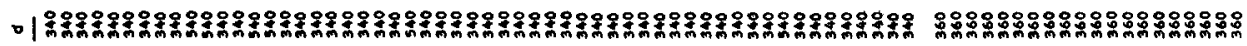

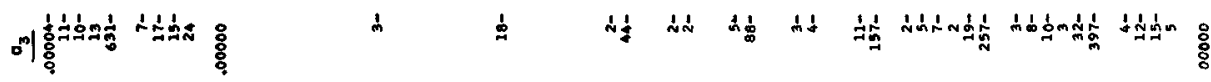

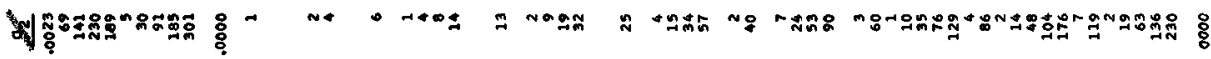

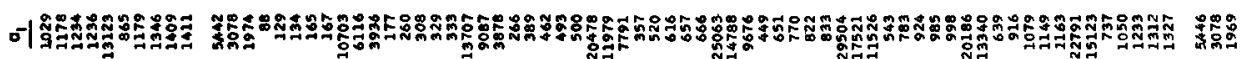
>

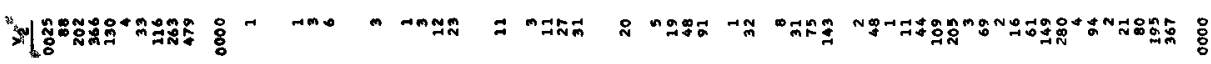

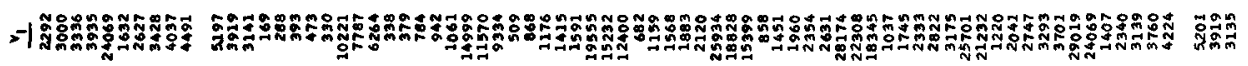

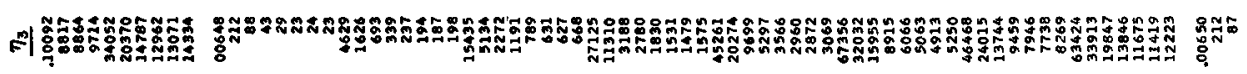

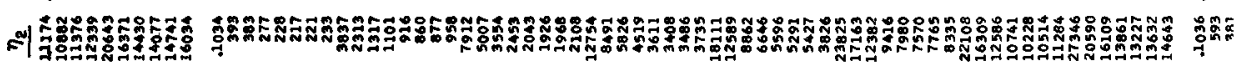

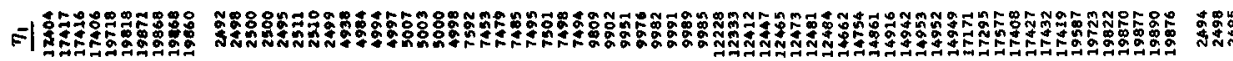

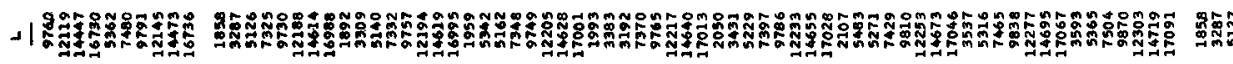

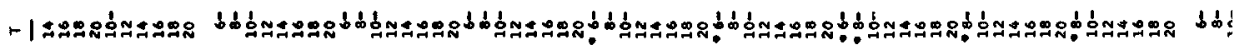
I |

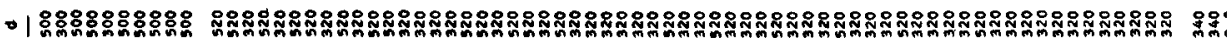


$\cdots$ THE USE OF THE STOKES-STRUIK APPROXIMATION $-i \sqrt{3}$ FOR WAVES OF FINITE HEIGHT

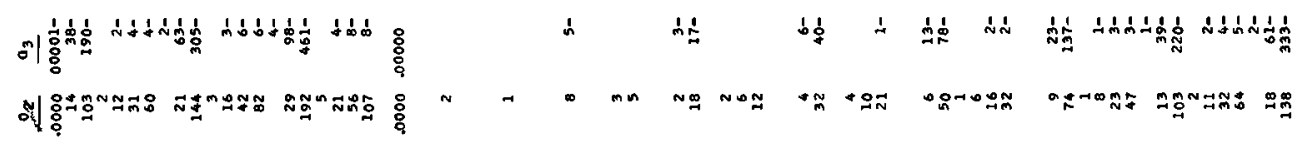

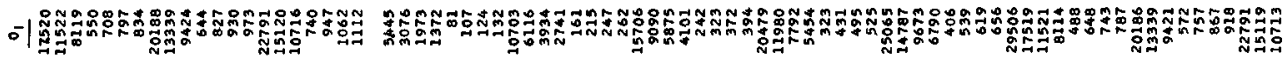

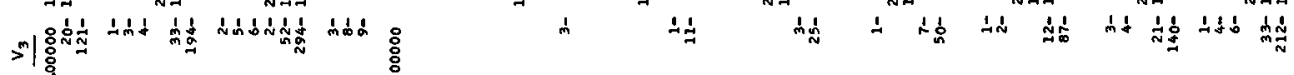

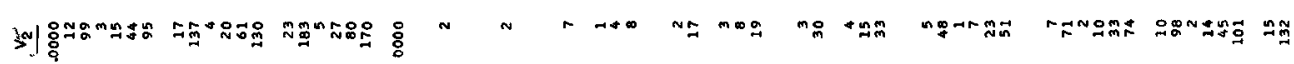

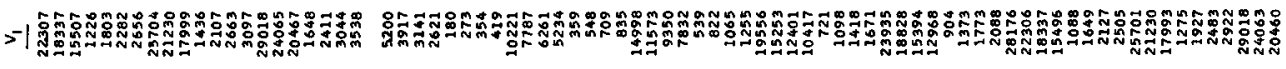

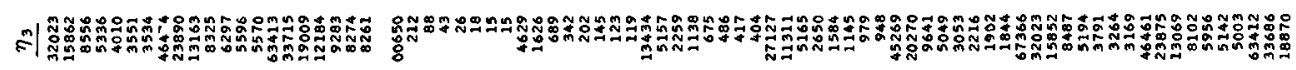

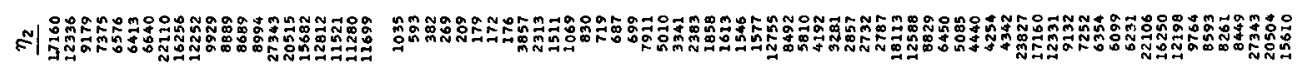

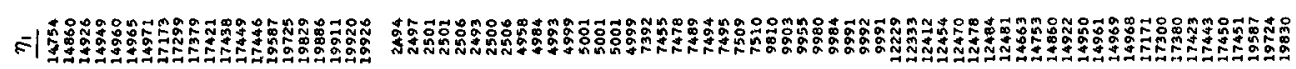

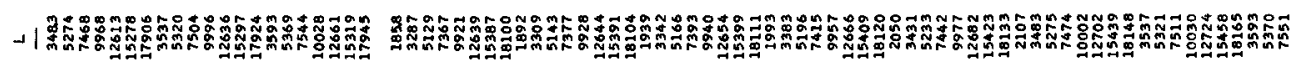

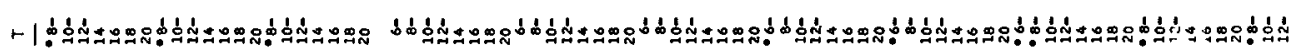

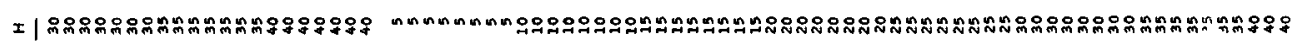

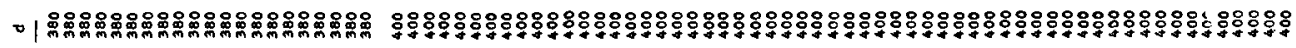

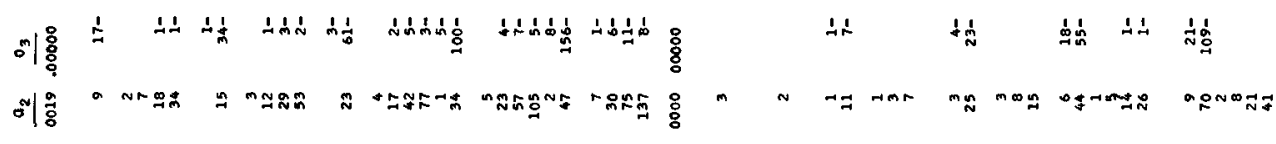

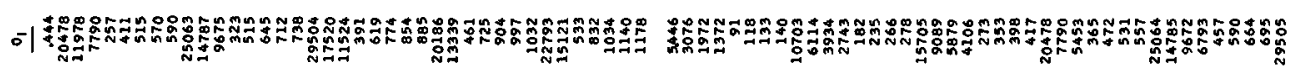

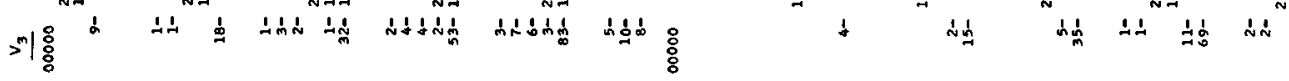

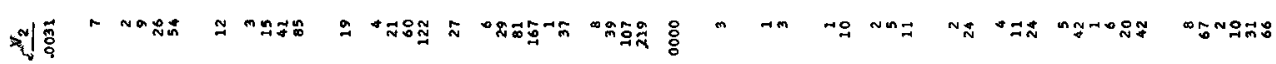

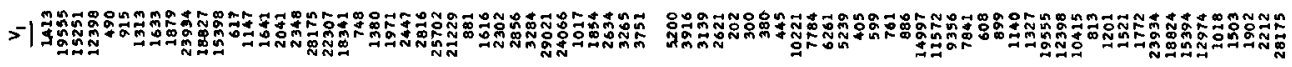

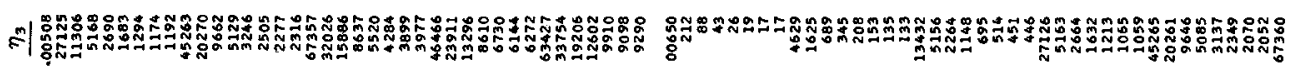

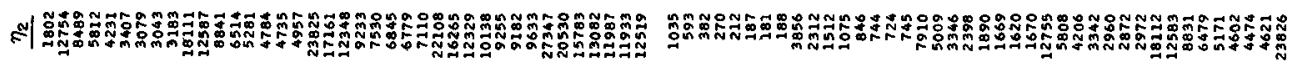

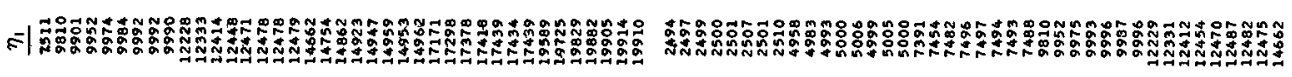

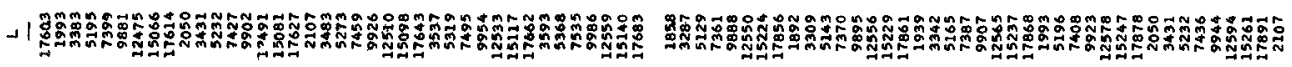
-1

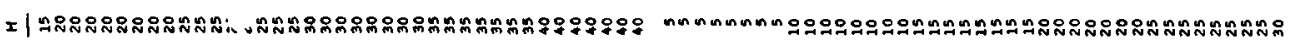

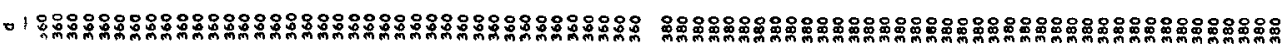




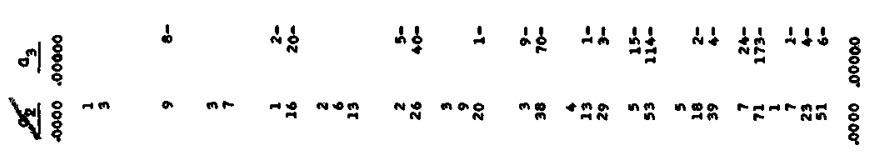

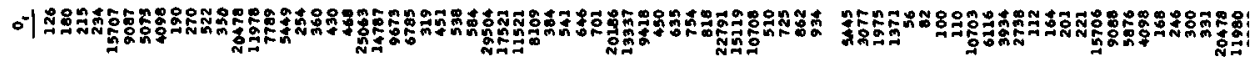

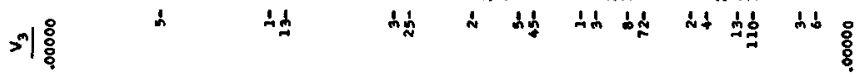

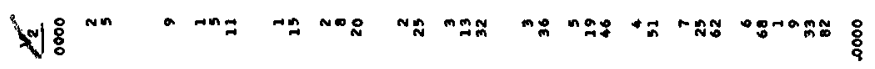

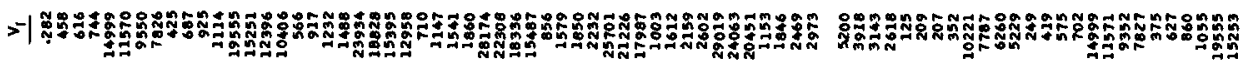

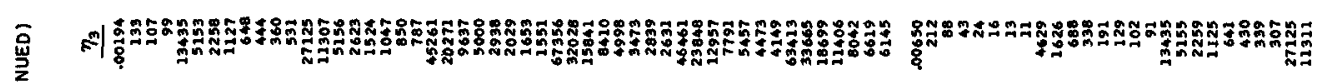

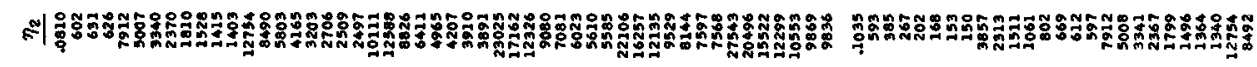

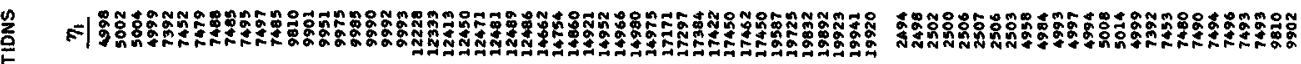

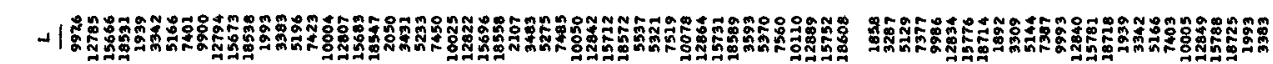

-1

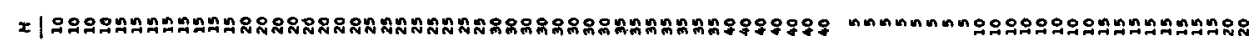

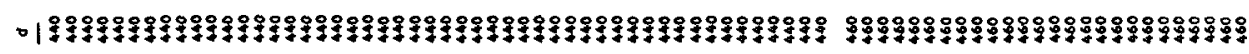

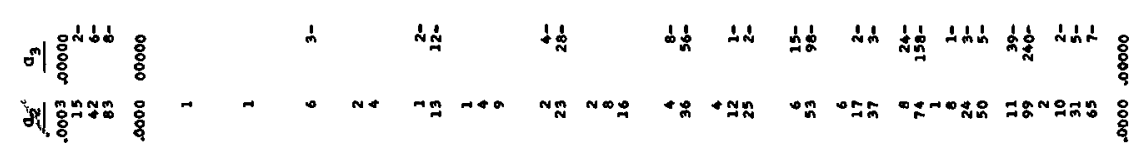

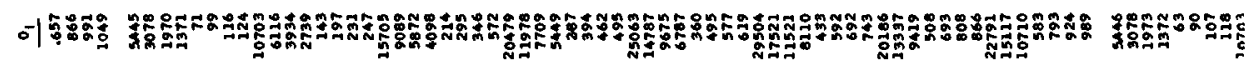

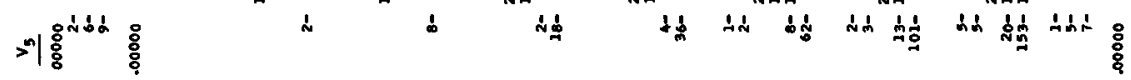

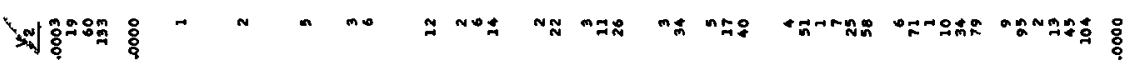

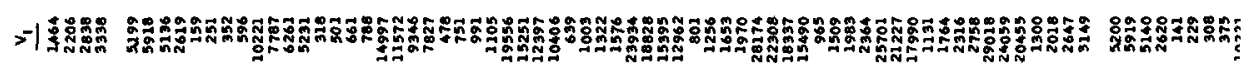

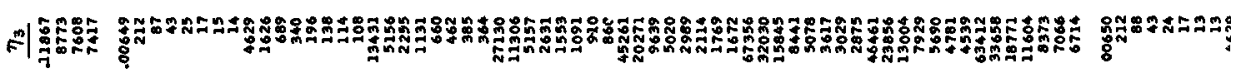

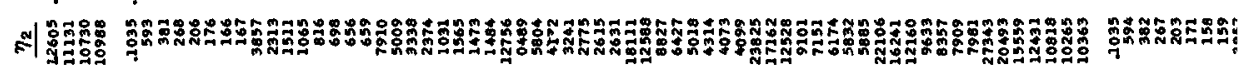

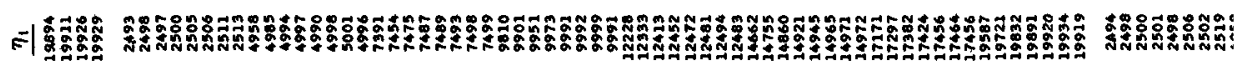

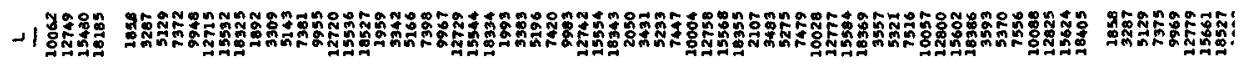

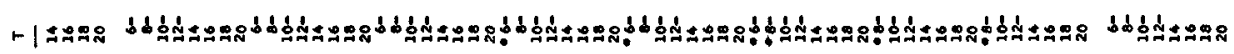

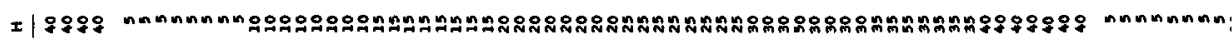

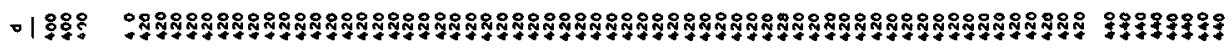


$x^{2} \times$ THE USE OF THE STOKES-STRUIK APPROXIMATION FOR WAVES OF FINITE HEIGHT

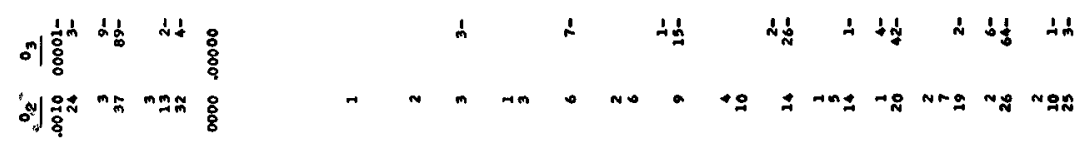

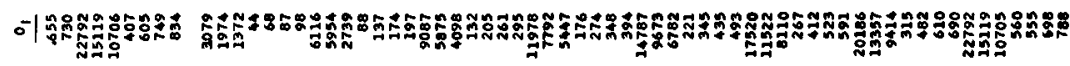

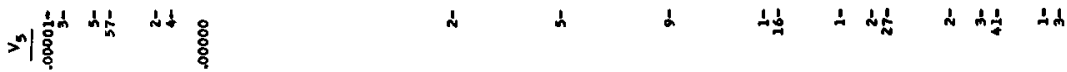

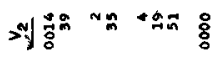

>|

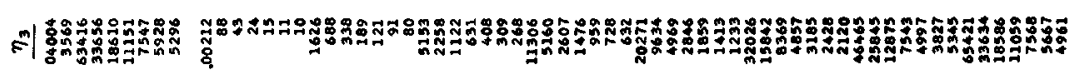

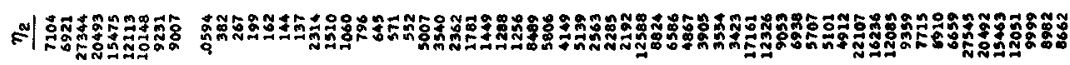

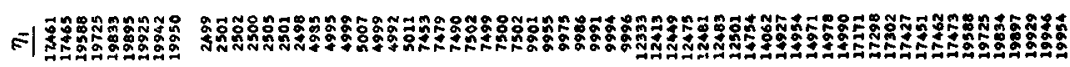

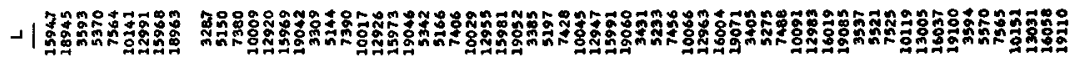
十|

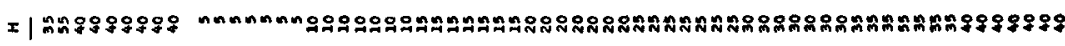

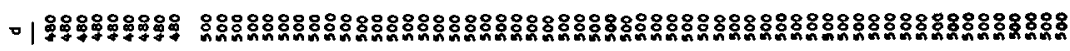

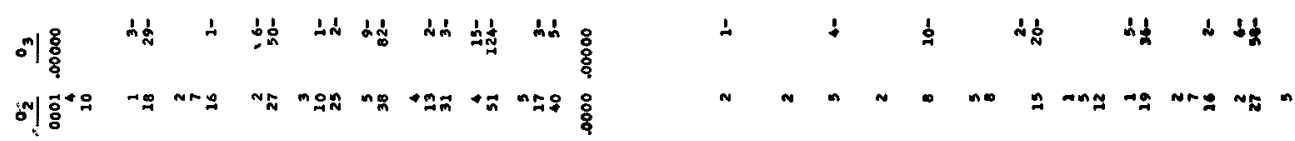

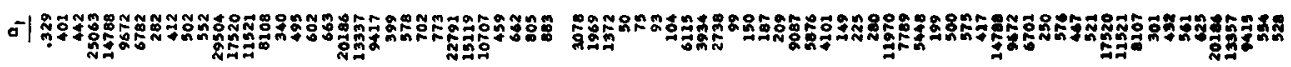

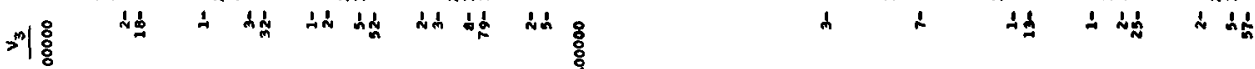
约

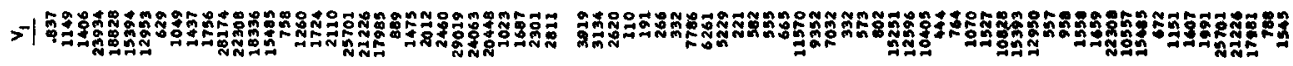

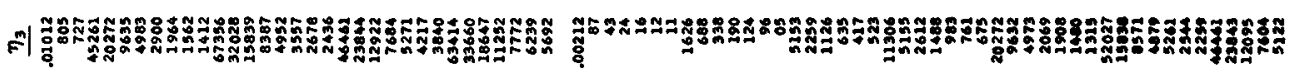

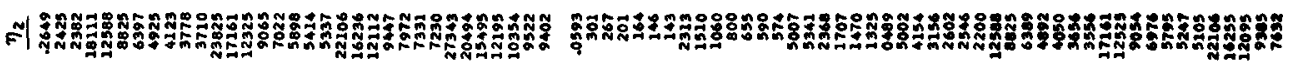

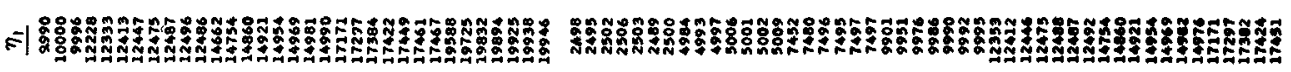

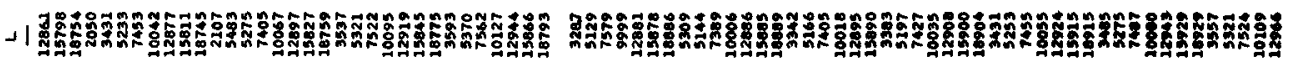
| | 1 -

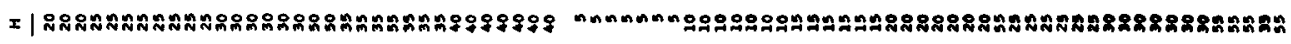

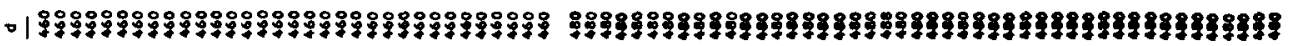




\section{COASTAL ENGINEERING}

\section{APPENDIX II}

Table 1 Circular Sines and Cosines for Integral Multiples of $\theta$

Table 2 Hyperbolic Sines and Cosines for Integral Multiples of $2 \pi z / L$

The decimal point position is indicated by the vertical lines. 
THE USE OF THE STOKES-STRUIK APPROXIMATION FOR WAVES OF FINITE HEIGHT

हैं

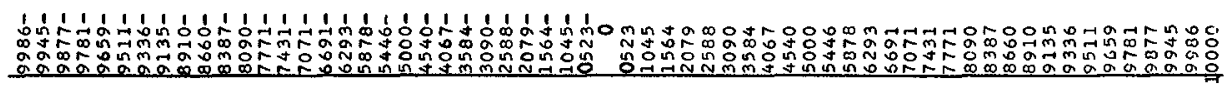
$\infty$

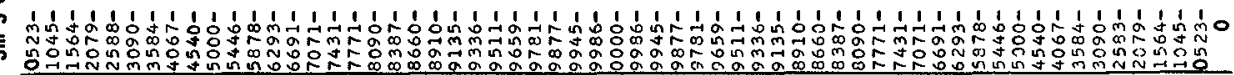

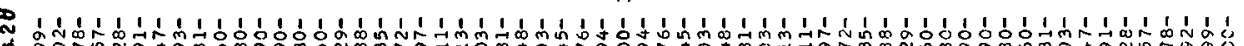

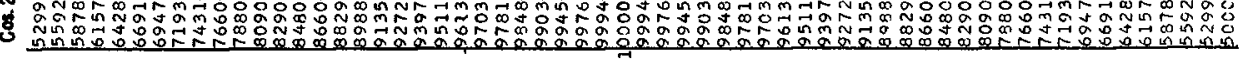
赵

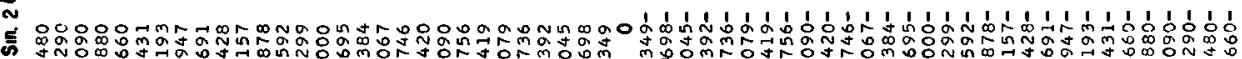

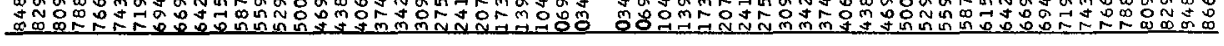

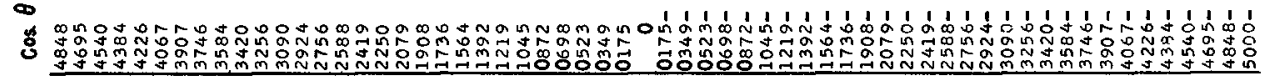
$\infty$

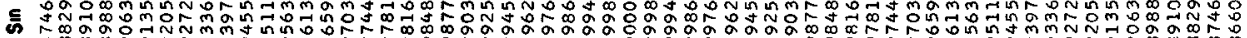
- wow

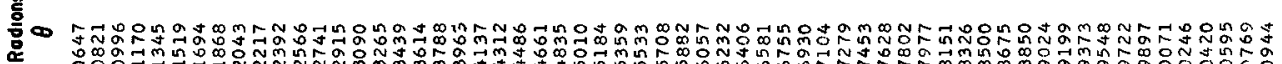
年

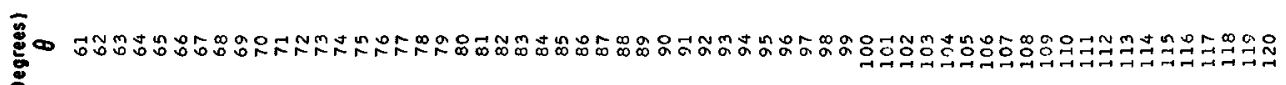
פ

m

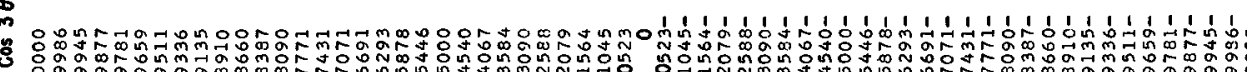
$\infty$

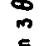

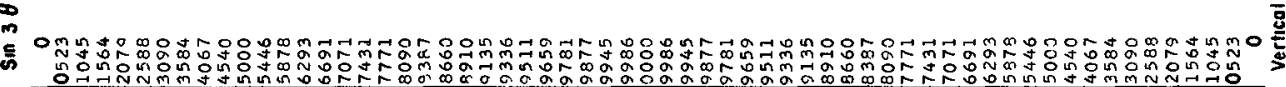

ㄱ.

范

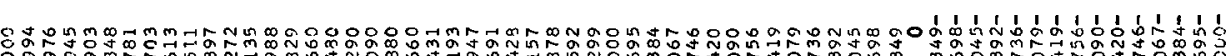
吸

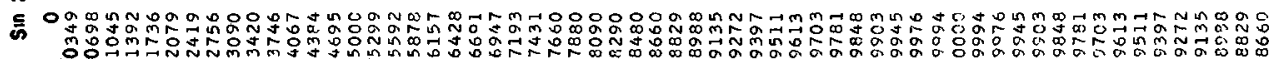
$\infty$

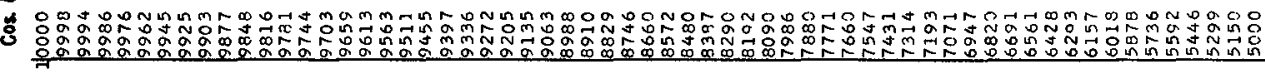
$\infty$

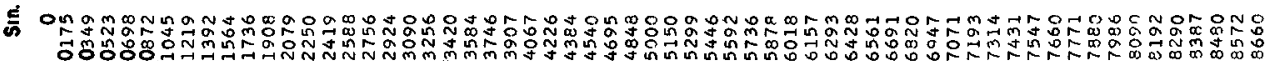

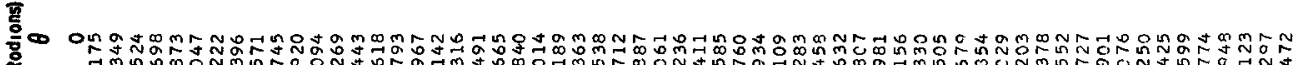

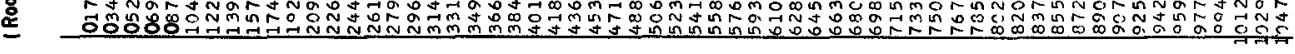

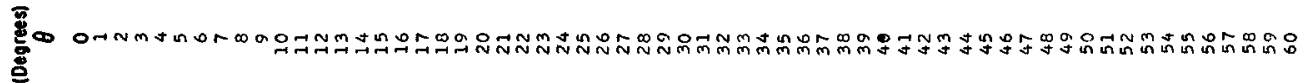




\section{COASTAL ENGINEERING}

m

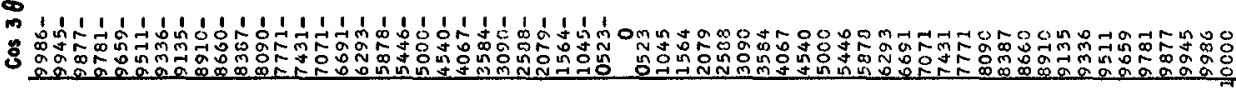

$\infty$

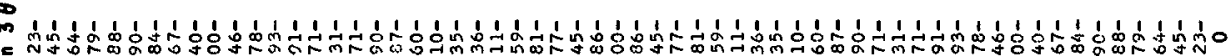

5

$\infty$

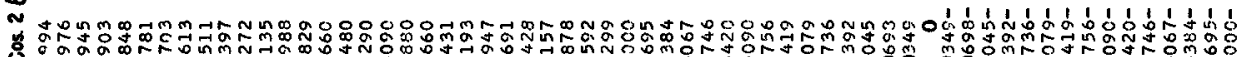

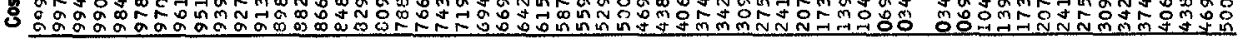

:

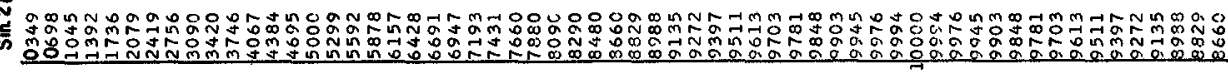

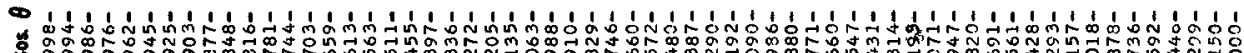

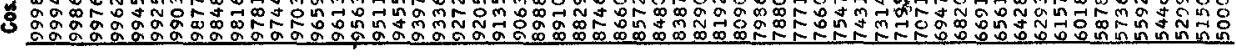

$\infty$

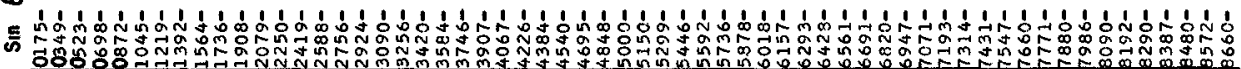

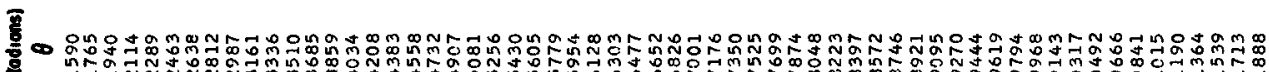

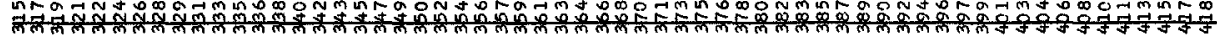

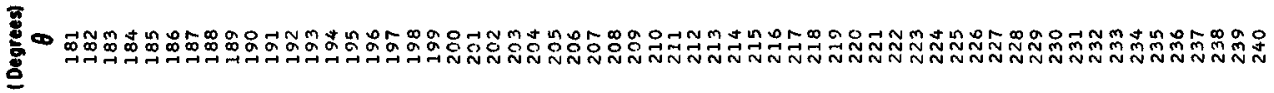

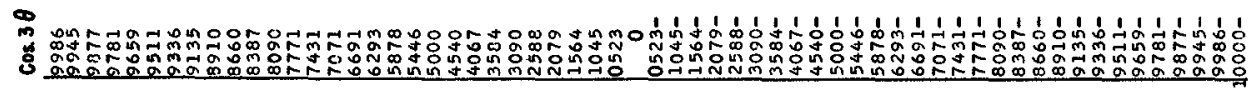

$\infty$

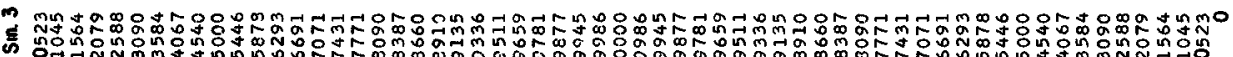

D

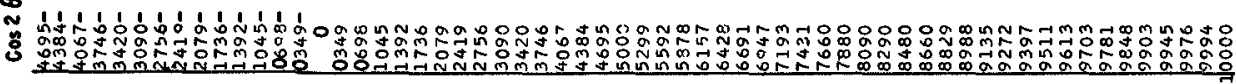

$\infty$

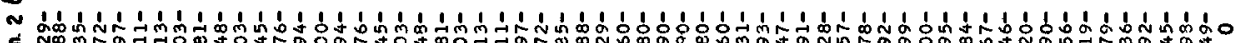

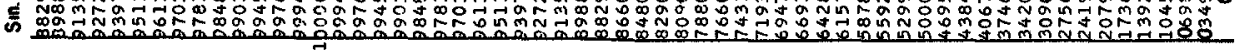

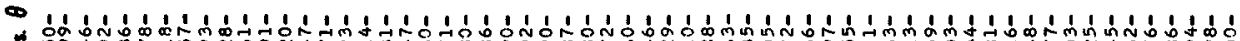

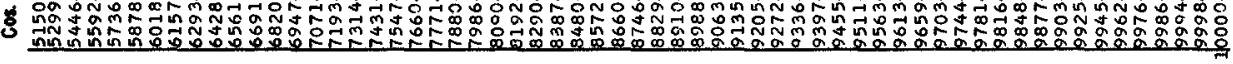

$\infty$

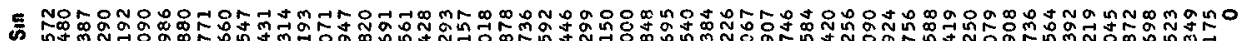

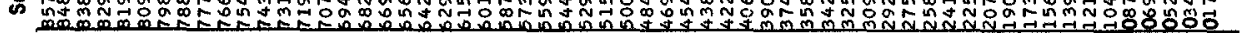

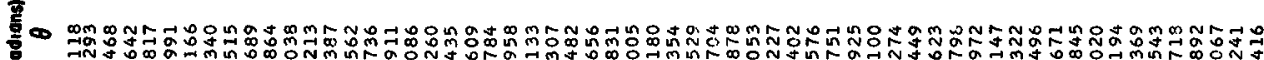

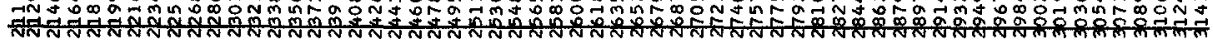

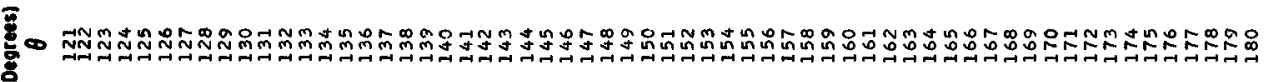


THE USE OF THE STOKES-STRUIK APPROXIMATION FOR WAVES OF FINITE HEIGHT

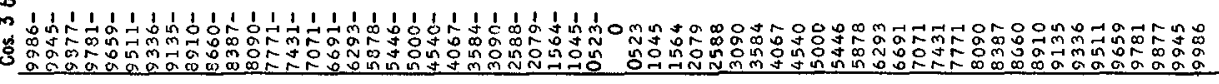
$\infty$

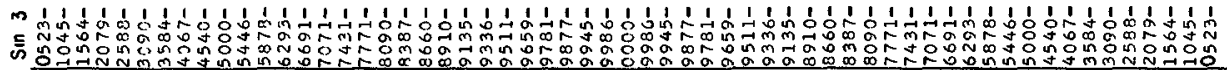

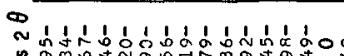

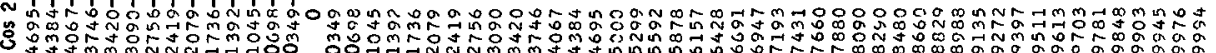
$\infty$

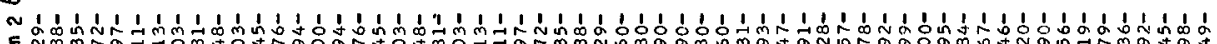

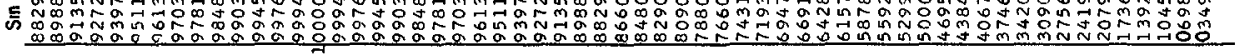
$\infty$

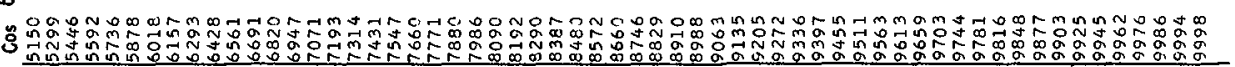
$\infty$

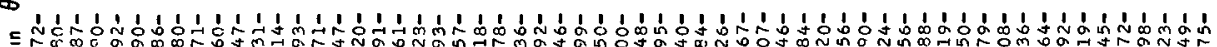

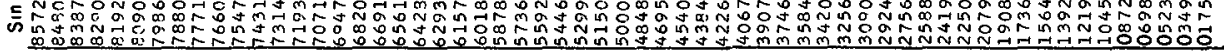

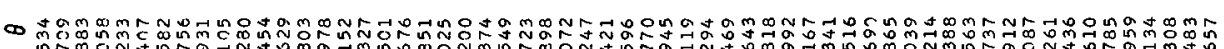

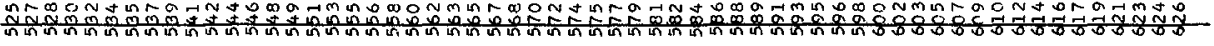

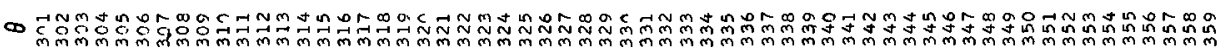

क

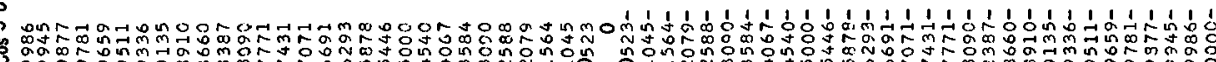
$\infty$

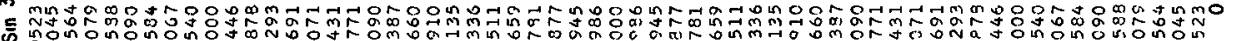

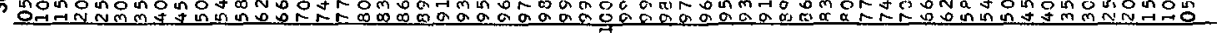

$\infty$

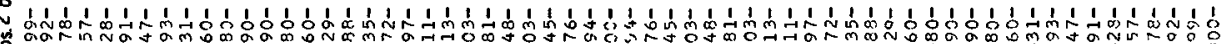

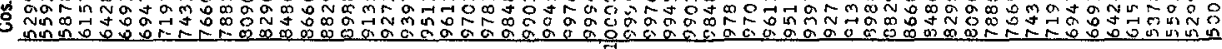
$\infty$

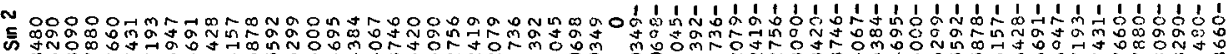

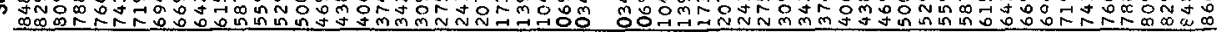

$\infty$

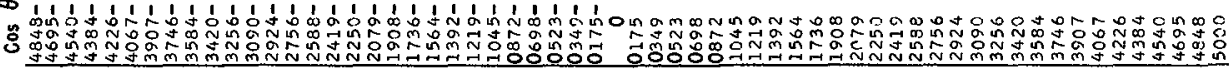

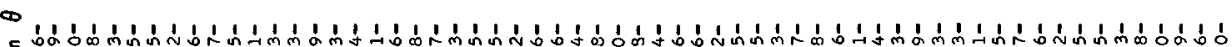

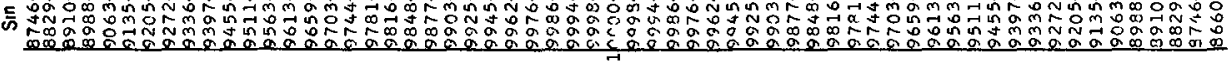
言

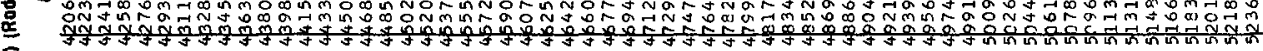

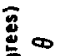

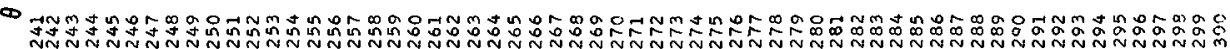


APPENDIX II

TAELE 2. HYPERBOLIC SINES \& COSINES FOR INTEGRAL MULTIPLES OF $2 \mathrm{mih}$

\begin{tabular}{|c|c|c|c|c|c|c|}
\hline$Z / L$ & $\sinh 2 \pi z / L$ & $\operatorname{Cosh} 2 \pi z / L$ & $\sinh 4 \pi z / L$ & $\operatorname{Cosh} 4 \pi z / L$ & $\sinh 6 \pi Z / L$ & $\operatorname{Cosh} 6 \pi z / L$ \\
\hline 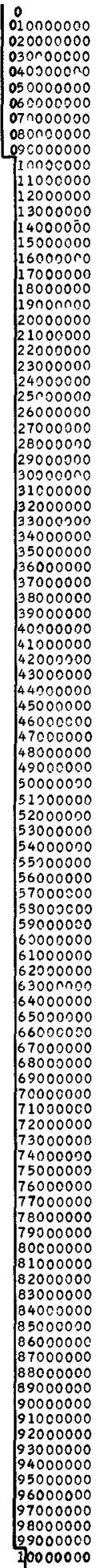 & 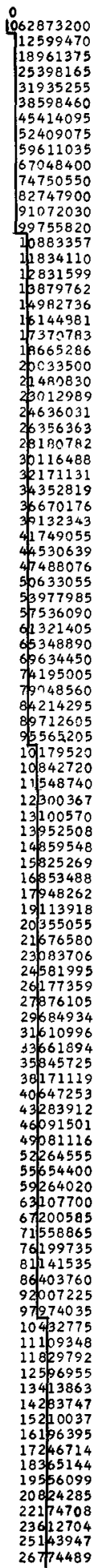 & 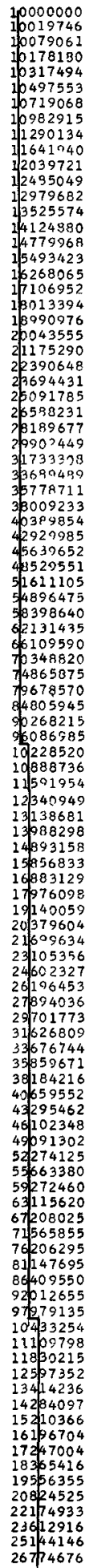 & 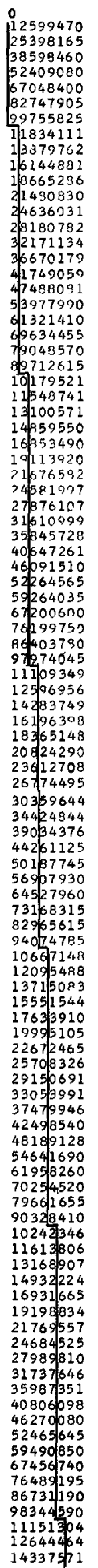 & 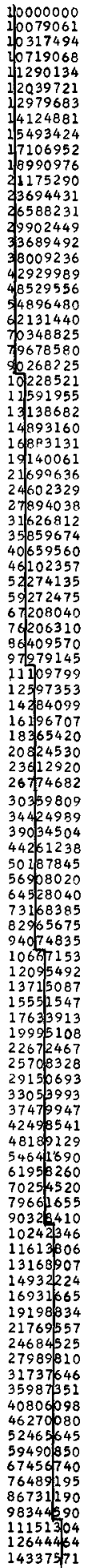 & 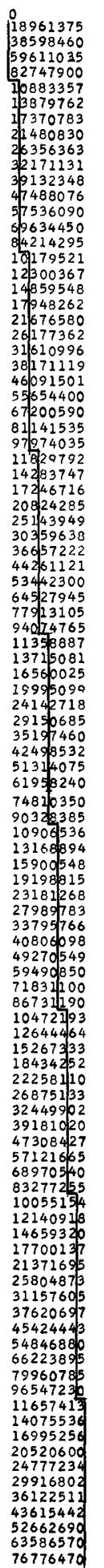 & 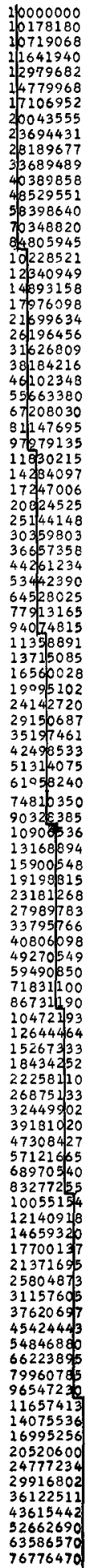 \\
\hline
\end{tabular}

